\title{
Transmembrane Mucins: Signaling Receptors at the Intersection of Inflammation and Cancer
}

\author{
Jos P.M. van Putten Karin Strijbis
}

Department of Infectious Diseases and Immunology, Utrecht University, Utrecht, The Netherlands

\section{Keywords}

Mucosal immunology · MUC1 · MUC3 · MUC4 · MUC12 . MUC13 $\cdot$ MUC16 $\cdot$ MUC17 $\cdot$ Post-translational modification · Extracellular domain · Ectodomain · Intracellular domain . Cytoplasmic tail · Intracellular signaling $\cdot \beta$-Catenin . Transcriptional modulation $\cdot$ Carcinogenesis $\cdot$ Metastasis

\begin{abstract}
Mucosal surfaces line our body cavities and provide the interaction surface between commensal and pathogenic microbiota and the host. The barrier function of the mucosal layer is largely maintained by gel-forming mucin proteins that are secreted by goblet cells. In addition, mucosal epithelial cells express cell-bound mucins that have both barrier and signaling functions. The family of transmembrane mucins consists of diverse members that share a few characteristics. The highly glycosylated extracellular mucin domains inhibit invasion by pathogenic bacteria and can form a tight mesh structure that protects cells in harmful conditions. The intracellular tails of transmembrane mucins can be phosphorylated and connect to signaling pathways that regulate inflammation, cell-cell interactions, differentiation, and apoptosis. Transmembrane mucins play important roles in preventing infection at mucosal surfaces, but are also re-
\end{abstract}

\section{KARGER}

E-Mail karger@karger.com www.karger.com/jin

\section{(C) 2017 The Author(s)}

Published by S. Karger AG, Basel

This article is licensed under the Creative Commons AttributionNonCommercial-NoDerivatives 4.0 International License (CC BYNC-ND) (http://www.karger.com/Services/OpenAccessLicense). Usage and distribution for commercial purposes as well as any distribution of modified material requires written permission. nowned for their contributions to the development, progression, and metastasis of adenocarcinomas. In general, transmembrane mucins seem to have evolved to monitor and repair damaged epithelia, but these functions can be highjacked by cancer cells to yield a survival advantage. This review presents an overview of the current knowledge of the functions of transmembrane mucins in inflammatory processes and carcinogenesis in order to better understand the diverse functions of these multifunctional proteins.

(c) 2017 The Author(s)
Published by S. Karger AG, Basel

\section{Introduction}

Mucosal surfaces line body cavities such as the gastrointestinal tract and lungs, protect against pathogens, and prevent dehydration. The epithelial cells that line the mucosa express a class of highly glycosylated proteins called mucins. Goblet cells secrete gel-forming mucins that form a viscous mucus layer that covers most mucosal surfaces and prevents penetration by bacteria. The composition of the mucus layer is highly variable. In the colon, the mucus layer consists of a porous outer layer with which commensal microbiota are associated and a dense inner layer that is essentially free of bacteria $[1,2]$. MUC2 is the

Dr. Karin Strijbis

Department of Infectious Diseases and Immunology, Utrecht University Yalelaan 1

NL-3584 CL Utrecht (The Netherlands)

E-Mail k.strijbis@uu.nl 
main soluble mucin expressed in the human duodenum, ileum, and colon, MUC5AC is highly expressed in the stomach, and MUC5AC and MUC5B are the soluble mucins present in the lungs.

Mucosal epithelial cells including goblet cells and enterocytes also express membrane-bound mucins, termed transmembrane mucins. Transmembrane mucins are large glycoproteins that localize to apical surfaces of epithelial cells that are in contact with relatively harsh environments. They are, for example, expressed in the intestinal tract, stomach, and respiratory system, but are also present on secretory epithelial cells of the liver, pancreas, gall bladder, kidney, salivary glands, lacrimal glands, and eye [3]. The family of transmembrane mucins consists of several members that differ in length, domain composition, and cytoplasmic signaling domain (Fig. 1). In healthy tissue, the large mucins MUC3, MUC4, MUC12, and MUC17 and the smaller MUC13 form the major components of the enterocyte glycocalyx. MUC1 is highly expressed in the stomach but also present in the colon. In the lungs, MUC1 and MUC16 are present (expression data human gene database: http://www.genecards.org; EMBL-EBI Expression Atlas: http://www.ebi.ac.uk/gxa/ home). Transmembrane mucins play important roles in maintaining mucosal barrier function and they prevent the invasion of pathogens at mucosal surfaces (Fig. 2a, b). They have also been implicated in the development of inflammatory bowel disease (Fig. 2c).

Transmembrane mucins have a receptor-like structure that is reminiscent of classical innate immune receptors. The highly glycosylated extracellular domain of transmembrane mucins has a barrier function whereas the intracellular domain can be phosphorylated and activate signal transduction pathways. The extracellular domain of transmembrane mucins can bind bacteria and can be shed from the epithelial surface. Shedding of the extracellular domain could be an activation signal that leads to phosphorylation of the intracellular domain and activation of mucin-specific signaling pathways that alter inflammatory responses, epithelial cell adhesion, differentiation, and apoptosis. While the functional link between binding/shedding of the extracellular domain and activation of the intracellular domain has not been conclusively established, it is likely that transmembrane mucins are signaling receptors that sense the external environment and activate intracellular signal transduction pathways essential for mucosal maintenance and damage repair.

In addition to their natural expression in mucosal tissues, transmembrane mucins are overexpressed by vari- ous adenocarcinomas, including colon, breast, pancreas, and ovarian cancer [4], in which they contribute to carcinogenesis and metastasis (Fig. 2d). The contribution of transmembrane mucins to carcinogenesis and metastasis is probably multifactorial. The transmembrane mucin intracellular domain directly links to signaling pathways that regulate cell differentiation, while the extracellular domain contributes to regulation of cell detachment and adhesion during metastasis and its barrier function protects against harmful environments and immune attack. The mechanisms that underlie the multifactorial functions of transmembrane mucins are poorly understood. In this review, we will discuss the normal function of transmembrane mucins in the maintenance and damage repair of epithelial tissues and their contribution to carcinogenesis. While the fields of enteropathogenic infections and carcinogenesis are very much separated in the literature, many of the observations regarding transmembrane mucins can be applied to both research areas. The aim of this review is to bring together knowledge on transmembrane mucin function from different fields in order to further our understanding of the contribution of transmembrane mucins to health and disease.

\section{General Features of Transmembrane Mucins}

The extracellular domains of transmembrane mucins are often composed of tandem repeat sequences rich in serine, threonine, and proline residues that are heavily O-glycosylated. The high level of glycosylation shields the protein backbone of the extracellular domain from proteolytic attack by bacteria and host proteases, and contributes to barrier formation. On the other hand, mucosal sugars such as fucose are released by certain microbiota and serve as a food source to maintain a healthy microbial community [5]. A wide range of oligosaccharide structures can be attached to mucins and the glycan composition of these structures can vary both within and between cell types due to the differential expression of glycosyltransferases. For instance, complex sugars such as sialyl-Lewis a, sialyl-Lewis c, sialyl-Lewis $\mathrm{x}$, and sialyl-Tn can be detected on the extracellular domain of MUC1 [6]. However, glycosylation is highly variable as differentially glycosylated MUC1 molecules can originate from a single precursor molecule within the same cell [7]. Expression of MUC1 by breast or pancreatic tissue results in different glycoforms that are differentially recognized by glycospecific antibodies [8-10].
282

J Innate Immun 2017;9:281-299 DOI: $10.1159 / 000453594$ van Putten/Strijbis 
Fig. 1. The transmembrane mucin family: domain structure of transmembrane mucins MUC1, MUC3, MUC4, MUC12, MUC13, MUC16, and MUC17. The extracellular domains often consist of very long internal repeat domains that are highly glycosylated. All transmembrane mucins except for MUC4 contain a SEA domain. At a conserved sequence in the SEA domain, transmembrane mucins can be autoproteolytically cleaved. The resulting N-terminal $\alpha$-chain and a $\mathrm{C}$-terminal $\beta$-chain remain noncovalently associated. Several transmembrane mucins contain EGF(-like) domains. The cytoplasmic tail domains of transmembrane mucins can be activated by phosphorylation and activate signaling pathways. The lower box contains the amino acid sequences of transmembrane mucin cytoplasmic tails marked for the phosphorylation potential. The red amino acids can be phosphorylated by known kinases as predicted by KinasePhos2.0 (http://kinasephos2.mbc.nctu. edu.tw). For the amino acids in large, bold, red font, phosphorylation was demonstrated by mass spectrometry as reported by PhosphoSitePlus (http://www.phosphosite.org/). Colors refer to the online version only.
Transmembrane mucin protein domains

․ Signal peptide

Epidermal growth factor(-like) domain

$\square$ Transmembrane domain

10 (Autoproteolytically cleaved) SEA domain

$\square^{k}$ Glycosylated internal repeat domain

( Cytoplasmic tail domain
NIDO domain (unknown function)

AMOP adhesion-associated domain

von Willebrand factor domain

PDZ-binding motif

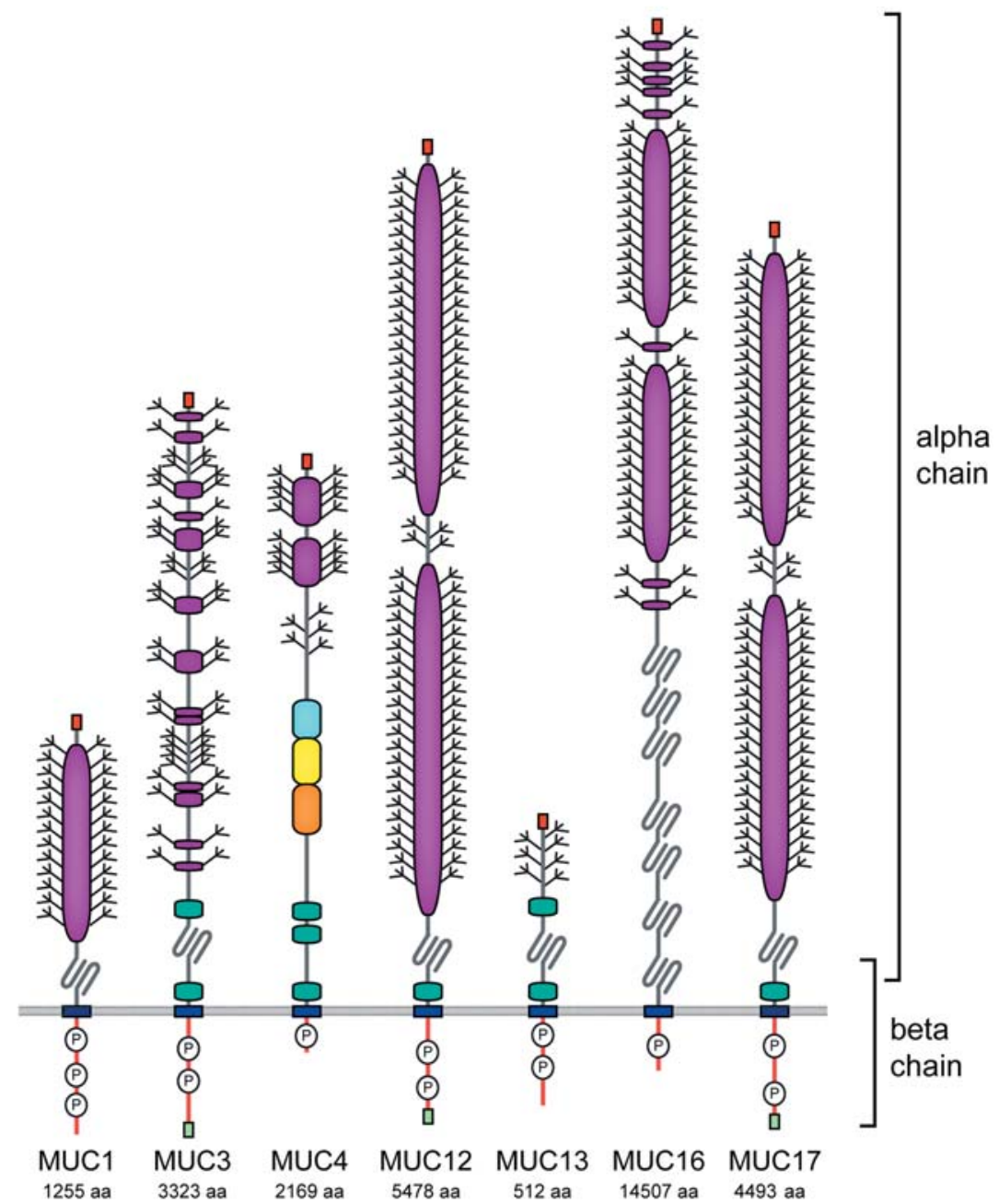

Phosphorylation potential of transmembrane mucin cytoplasmic tails

MUC1 - avcqcrrknygqldifpardtyhpmSeyptyhthgry vppsstdrSpyekvSagnggssISytnpavaatsanl MUC3 - rsgwwggqrrgrswdqdrkwfetwdeevvgifsnwgfeddgtdkdtnfyvalenvdttmkvhikrpemtsssv

MUC4 - gcsgarfsyfinsaealp

MUC12 - sqrkrhreqydvpqewrkegtpgifqktaiwedqniresrfglenaynnfrptletvdsgtelhiqrpemvastv MUC13 - tarsnnktkhieeenlidedfqnlkIrstgftnlgaegSvfpkvritasrdsqmqnpySshsSmprpdy

MUC16 - vttrrrkkegeynvqqqcpgyyqShldledlq

MUC17 - rskrevkrqkyrlsqlykwqeedsgpapglfqnigfdicqdddsihlesiysnfqpslrhidpetkiriqrpqvmitsf 
a Healthy colon mucosa

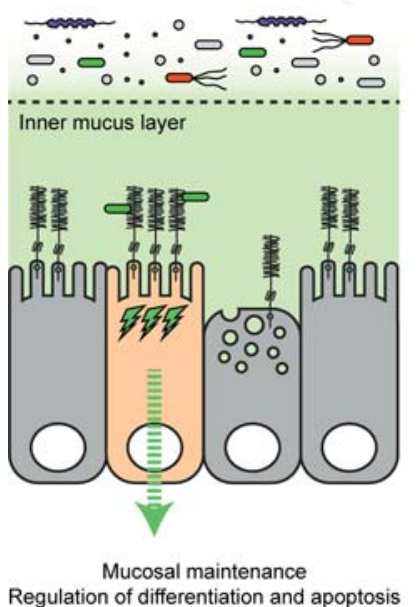

b Invasive enterobacteria

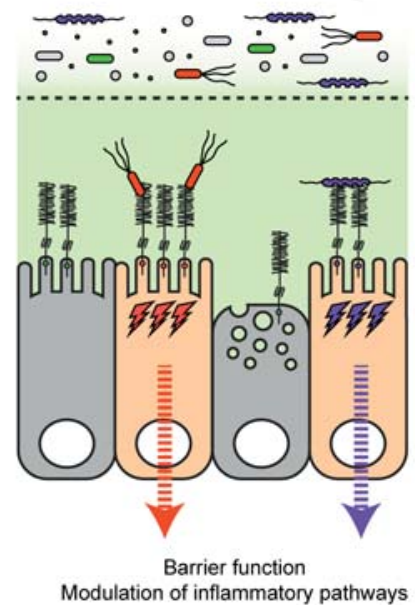

C

Inflammatory bowel disease

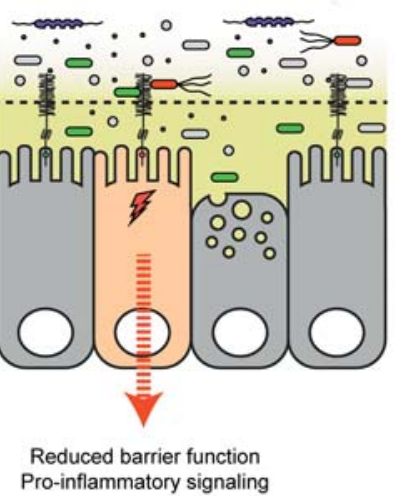

d Carcinogenesis

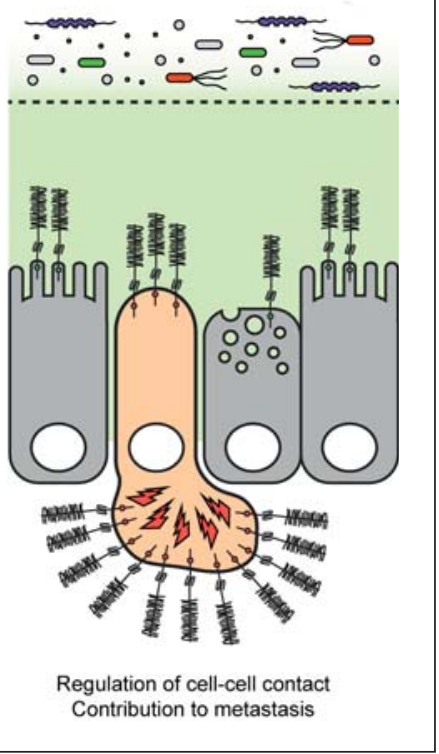

Fig. 2. Functions of transmembrane mucins in the human colon. a In healthy colon epithelial mucosa, the soluble mucus layer consists of an outer and inner mucus layer. While microbiota are associated with the outer layer, the inner layer is relatively sterile. Within the inner mucus layer, transmembrane mucins are expressed on the apical membrane of colonocytes and goblet cells. Transmembrane mucins contribute to mucosal maintenance and the regulation of epithelial cell differentiation and apoptosis. $\mathbf{b}$ The glycosylated extracellular domains of transmembrane mucins limit invasion by enteropathogens such as $S$. enteritidis and C. jejuni. Transmembrane mucin cytosolic tails are signaling domains that modulate inflammatory pathways, including NF- $\mathrm{BB}$, and the expression of pro- and anti-inflammatory cytokines. c Mutations in transmembrane mucins or defects in mucin glycosylation are associated with inflammatory bowel disease. Reduced mucosal barrier function leads to interactions between epithelial tissue and luminal microbiota and increased proinflammatory signaling. $\mathbf{d} \mathrm{Ab}$ errant or overexpression of transmembrane mucins is a prominent feature of adenocarcinomas such as colon, breast, pancreatic, and ovarian cancer. Overexpression leads to the loss of polarity and is associated with poor prognosis. Transmembrane mucins regulate cell-cell contact and thereby contribute to metastasis.

\section{The Extracellular Mucin Domain}

The extracellular domains of most transmembrane mucins contain a sea urchin sperm protein, enterokinase and agrin (SEA) domain [11]. The SEA domain is autoproteolytically cleaved in the endoplasmic reticulum [12] resulting in a mucin $\alpha$ - and a $\beta$-chain that are connected by parallel $\beta$-sheets [13] (Fig. 1). Mature transmembrane mucins are therefore composed of an extracellular $\alpha$-chain and a transmembrane/intracellular $\beta$-chain that are noncovalently associated. Transmembrane mucins MUC1, MUC3, MUC12, and MUC17 all contain SEA domains with a conserved G-S[V/I]VV cleavage motif [14]. One of the functions of the SEA domain may be to protect epithelial cells against mechanical force. Application of force results in disruption of the SEA domain before rupture of the epithelial apical membrane [15]. Another function of the SEA domain may be to release the transmembrane mucin extracellular domain (Fig. 3a). Mucin extracellular domains can be detected in biological fluids such as serum, the lumen of the intestinal tract, and culture supernatants of mucin-expressing cells. Excessive shedding of transmembrane mucin extracellular domains is often observed for metastatic carcinoma [16] and during inflammatory bowel disease $[17,18]$ and cystic fibrosis [19].

Mutation of the MUC1 SEA domain G-S cleavage site to G-A prevents release of the extracellular domain [20, 21]. MUC4 lacks a typical SEA domain but is proteolytically cleaved in the endoplasmic reticulum and this cleavage is essential for maturation of the MUC4 complex [22]. Cleavage of MUC4 might occur in a nonenzymatic manner at the GD-PH sequence in the VWD domain as is observed for soluble mucins MUC2 and MUC5AC [23, 24]. MUC13 contains a SEA domain without a conserved cleavage motif, but gel analysis showed that the mature protein does consist of 2 polypeptides [25]. Cleavage of MUC16 does not occur in a conserved sequence in 1 of 


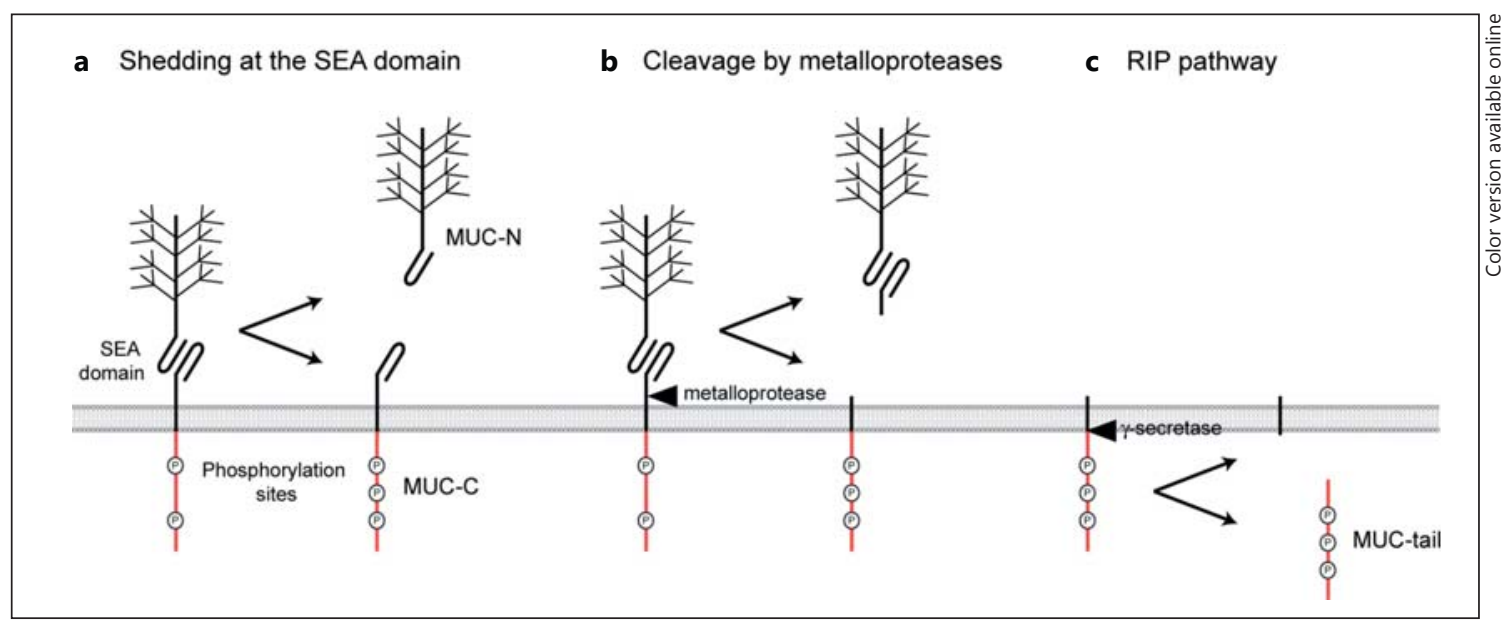

Fig. 3. Shedding and cleavage of transmembrane mucins. Transmembrane mucin extracellular domains can be released from the surface and can be detected in many biological fluids. The intracellular tail, and in some cases the full-length protein, is reported to localize to the nucleus. Several mechanisms of transmembrane mucin shedding and cleavage have been reported. a Shedding of the transmembrane mucin extracellular domain from the SEA do- main. b Cleavage of the extracellular domain by metalloproteases or sheddases. It remains to be established if release of the extracellular domain leads to phosphorylation and activation of the intracellular tail and the initiation of signaling pathways. c RIP pathway; cleavage of the intracellular tail by a $\gamma$-secretase after release of the extracellular domain. the SEA domains, but occurs close to the transmembrane domain [26]. This cleavage occurs in an acidic compartment of the Golgi complex and is independent of the amino acid sequence as mutation still resulted in cleavage. An alternative mechanism to release the mucin extracellular domain is proteolytic cleavage close to the plasma membrane by sheddases or metalloproteases such as TACE/ ADAM17 and MT1-MMP [27, 28] (Fig. 3b). The triggers and mechanisms involved in release of the ectodomain are only partially understood. It has been hypothesized that mucin extracellular domains are released in response to mechanical force, interactions with microbes or alteration in $\mathrm{pH}$, ionic concentration, hydration [4] or inflammatory stimuli such as TNFa and neutrophil elastase [29]. At the mucosal surface, the shed domains might function as decoy receptors for pathogens. It is possible that disruption of the SEA domain or release of the extracellular domain by sheddases can be sensed by the cell and activates signaling by the cytoplasmic tail. An inhibitory function of the extracellular domain on signaling by the intracellular domain has been described for mucin-type glycoproteins involved in cell differentiation in the yeasts Saccharomyces cerevisiae and Candida albicans [30, 31].

The growth factor EGF is produced by salivary glands and regulates mucosal repair and mucin expression throughout the gastrointestinal and respiratory tracts [32, 33]. The extracellular domains of most transmembrane mucins contain epidermal growth factor (EGF)-like domains. In MUC3, MUC12, MUC13, and MUC17 the EGF domains flank the mucin SEA domain, but MUC4 lacks a SEA domain and has 3 predicted EGF domains (Fig. 1). EGF domains of transmembrane mucins can interact with EGF receptors and activate receptor signaling, as has been shown for MUC4 [34-38]. It has been proposed that release of the extracellular domain enables mucin EGF domains in both the $\alpha$ - and $\beta$-chain to interact with their ligands on EGF receptors [39]. The released mucin extracellular $\alpha$-domain may therefore have a biologically active role at more distant sites, similar to cytokines [4]. Membrane-bound and EGF domain-containing $\beta$-chains of transmembrane mucins can interact with adjacent EGF receptors and increase their activity, as was shown for MUC4 and the ERBB2 receptor [34].

\section{The Intracellular Mucin Domain}

The cytoplasmic tails of the large transmembrane mucins MUC3, MUC12, and MUC17 contain PDZ-binding motifs that are instrumental in the trafficking and anchoring of receptor proteins and organize signaling complexes at cellular membranes $[40,41]$. Through the PDZbinding motif, these mucins are functionally linked with the cystic fibrosis transmembrane conductance regulator (CFTR) chloride channel that also contains a PDZ-binding motif. Because MUC3 and CFTR compete for a single

J Innate Immun 2017;9:281-299 DOI: $10.1159 / 000453594$ 
PDZ-binding domain in adaptor protein GOPC that targets proteins for lysosomal degradation, overexpression of either MUC3 or CFTR increases trafficking of the other protein to the plasma membrane [42]. Stimulation with the cholinomimetic drug carbachol leads to recruitment of CFTR to the plasma membrane, but internalization of MUC17. MUC3 and MUC12 localization is not affected by carbachol stimulation [43]. The authors hypothesize that MUC17 internalization could mediate the uptake of bacteria into epithelial cells [44].

Similar to classical (immune) receptors, the intracellular tails of transmembrane mucins link to signaling pathways. MUC1 is the most well-studied transmembrane mucin and several intracellular signaling pathways are associated with its cytoplasmic tail. The intracellular tails of all transmembrane mucins contain putative phosphorylation sites, but we must emphasize that they are dissimilar in sequence and length and do not contain any conserved domains (Fig. 1). These observations suggest a high degree of functional divergence and most likely signaling specificity between different transmembrane mucins. The cytoplasmic tail of MUC1 can be phosphorylated at several conserved tyrosines $[45,46]$ and it was convincingly shown that interactions of the MUC1 tail with other proteins are mediated by phosphorylation [47-49]. For example, the phosphorylated MUC1 cytoplasmic tail competes with E-cadherin for the binding of $\beta$-catenin. The $\beta$-catenin/E-cadherin complex stabilizes cell-cell interactions, and phosphorylation of the MUC1 tail therefore stimulates cell detachment and anchorageindependent growth [50]. MUC13 is phosphorylated in unstimulated intestinal epithelial cells [51], but the involved amino acids remain to be identified. Phosphorylation of several tyrosine, threonine, and serine residues in the tails of different transmembrane mucins has been confirmed by mass spectrometry as reported on the PhosphoSitePlus database (http://www.phosphosite.org/; Fig. 1). The next challenge in this field is to uncover the signaling pathways that link to different transmembrane mucins.

In addition to signaling from the plasma membrane, MUC1, MUC13, and MUC16 have been reported to localize to the nucleus. The cytoplasmic tail of MUC1 can be released from the membrane and modulate the function of transcription factors and regulatory proteins. The mechanisms of MUC1 tail release from the membrane are unclear. One potential mechanism may involve regulated intramembrane proteolysis (RIP). RIP includes proteolytic release of the ectodomain by a membrane-associated metalloprotease followed by $\gamma$-secretase-mediated cleav- age of the cytoplasmic tail and translocation to the nucleus [52] (Fig. 3c). The RIP pathway activates the mucinlike protein CD43, but MUC1 does not seem to be cleaved in a $\gamma$-secretase-dependent manner [53]. Whether the cytoplasmic tails of other transmembrane mucins can be released from the plasma membrane and if the RIP pathway is involved remains to be established.

In summary, mature transmembrane mucins generally consist of an extracellular $\alpha$-chain and a $\beta$-chain that contains the transmembrane domain and the cytoplasmic tail (Fig. 1). Several processing events and cleavage possibilities can generate transmembrane mucin fragments of different sizes, presumably with specific functions (Fig. 3). Functional diversity of transmembrane mucins can also be achieved by splice variants that contain selected domains. For MUC1, more than 20 transcript variants have been described. Specific MUC1 variants are associated with mucin expression $[54,55]$, cytokine production [56] or carcinogenesis $[57,58]$. Table 1 summarizes the known functions of transmembrane mucins $\alpha$ - and $\beta$-domains in healthy mucosal tissue and in cancer cells.

\section{Barrier Function, Mucosal Maintenance, and Interactions with Mucosal Pathogens}

Under healthy conditions, the extended domains of transmembrane mucins form the dense enterocyte glycocalyx that is impermeable to virus- or bacteria-sized particles [59]. The glycosylated tandem repeats of MUC1 and MUC16 can extend $200-500 \mathrm{~nm}$ and $700 \mathrm{~nm}$ above the cell surface, respectively $[60,61]$. Very long transmembrane mucins such as MUC12, MUC16, and MUC17 may serve as initial contact and a first layer of defense, while the shorter transmembrane mucins may detect invasive pathogens that have come into close range of the enterocyte [44]. In the lungs, MUC1 is expressed on microvilli, MUC4 and MUC20 on cilia, and MUC16 on goblet cells. The microorganization of these transmembrane mucins creates a space-filling barrier that is selective to larger viral particles [62]. In the intestinal tract or at other mucosal surfaces, epithelial damage caused by bacterial invasion or mechanical stress can cause shedding of the transmembrane mucin extracellular domain, loss of barrier function, and initiation of signaling pathways involved in mucosal maintenance. The exact roles of the different transmembrane mucins during mucosal maintenance of healthy and inflamed tissue remain to be addressed. However, the specificity of transmembrane mucin function is
286

J Innate Immun 2017;9:281-299 DOI: $10.1159 / 000453594$ van Putten/Strijbis 
Table 1. General functions of transmembrane mucin domains

\begin{tabular}{|c|c|c|}
\hline & Healthy mucosal tissue & Cancer cells \\
\hline Extracellular $a$-chain, attached & $\begin{array}{l}\text { Barrier function } \\
\text { Resistance to harmful conditions and toxic compounds } \\
\text { Dampening of immune responses by receptor shielding }\end{array}$ & $\begin{array}{l}\text { Barrier function } \\
\text { Protection in hostile conditions during metastasis } \\
\text { Increased drug resistance } \\
\text { Regulation of cell-cell contact by receptor shielding }\end{array}$ \\
\hline Extracellular $\alpha$-chain, shed & Decoy receptor for invasive pathogens & $\begin{array}{l}\text { Cancer progression biomarker } \\
\text { Activation of EGF receptors }\end{array}$ \\
\hline $\begin{array}{l}\beta \text {-Chain, plasma } \\
\text { membrane }\end{array}$ & $\begin{array}{l}\text { Phosphorylation of cytoplasmic tail } \\
\text { Activation of pro- or anti-inflammatory pathways and } \\
\text { cytokine secretion } \\
\text { Modulation of the NF- } \kappa \mathrm{B} \text { pathway } \\
\text { Inflammasome regulation } \\
\text { Regulation of cell proliferation and apoptosis }\end{array}$ & $\begin{array}{l}\text { Phosphorylation of cytoplasmic tail } \\
\text { Regulation of cell-cell contact through } \\
\text { E-cadherin/ } \beta \text {-catenin } \\
\text { Interaction with EGF receptors } \\
\text { Stimulation of cell proliferation and blocking of } \\
\text { apoptosis }\end{array}$ \\
\hline $\begin{array}{l}\beta \text {-Chain/cytoplasmic } \\
\text { tail, nucleus }\end{array}$ & Not described, similar potential as in cancer cells? & $\begin{array}{l}\text { Interaction with transcription factors } \\
\text { Transcriptional regulation }\end{array}$ \\
\hline
\end{tabular}

illustrated by a study in which enterobacterial infections lead to the upregulation of MUC1 in the distal colon, while expression of MUC3, MUC4, and MUC13 was decreased [63]. It can be imagined that epithelial damage leads to transmembrane mucin activation and, more specifically, that interaction of microbiota with mucin extracellular domains leads to tailored signaling by mucin intracellular domains. In this scheme, bacterial components are the ligands that bind the mucin extracellular domain and initiate receptor signaling.

\section{Interactions between Transmembrane Mucins and Mucosal Pathogens}

A protective role of transmembrane mucins during bacterial invasion has been most convincingly demonstrated in the context of MUC1 and the bacterial pathogen Helicobacter pylori. This pathogen is well known for its ability to colonize the stomach and initiate precancerous processes at the site of infection. $H$. pylori expresses BabA and SabA adhesins that bind to Lewis b and sialylLewis x glycan structures of gastric mucins [64], and $H$. pylori directly binds to mouse MUC1 [65]. Released MUC1 extracellular domain can act as a soluble decoy that prevents $H$. pylori attachment to epithelial cells [66]. While both extracellular and intracellular MUC1 domains can be detected in healthy stomachs, the MUC1 extracellular domain is not detectable on the apical site of stomach epithelial cells of $H$. pylori-positive gastritis patients, suggesting shedding of the extracellular domain [67]. These data may indicate that release of the MUC1 extracellular domain is a direct result of $H$. pylori infection.

Transmembrane Mucins
Epithelial MUC1 also plays a protective role during infection with the major bacterial foodborne pathogen Campylobacter jejuni. MUC1 knockout mice are more susceptible to gastrointestinal C. jejuni infection [68]. Because hematopoietic cells also express MUC1, bone marrow chimeric mice were used in this study to ensure the phenotype was due to the contribution of epithelial mucins. The same MUC1 knockout mice did not show increased susceptibility to Salmonella typhimurium infection, presumably because this pathogen preferentially invades $M$ cells [68] that are covered with a more permeable mucus [69]. The pathogenic bacterium Pseudomonas aeruginosa is often associated with mucosal infections in cystic fibrosis patients. MUC1 was proposed to play an immunosuppressive role during $P$. aeruginosa infection in the lung as MUC1 knockout mice more rapidly clear $P$. aeruginosa from the lungs and display stronger immune responses [70]. However, in a different study using a repetitive infection model, MUC1 knockout mice were shown to be more susceptible to $P$. aeruginosa infection [71]. It is conceivable that the differences in outcome between these studies relates to changes in immune cell activation or mucin depletion and/or shedding in the case of the repetitive infection model. Interestingly, $P$. aeruginosa induces phosphorylation of the MUC1 intracellular tail and this phosphorylation is dependent on the EGFR receptor $[72,73]$.

A few examples of mucin-bacterial interactions are available for transmembrane mucins other than MUC1. Exposure to enterotoxigenic Escherichia coli (ETEC) induces the expression of transmembrane mucins MUC3 and MUC4 to increase barrier formation [74]. In re-

J Innate Immun 2017;9:281-299 DOI: $10.1159 / 000453594$ 
sponse, ETEC and also Vibrio cholerae secrete a metalloprotease YghJ that degrades MUC3, thus allowing access to enterocytes and delivery of heat-labile toxin [75]. Probiotic Lactobacillus strains can also upregulate the expression of transmembrane MUC3, and these bacteria induce release of the MUC3 extracellular domain [76]. Transmembrane MUC13 prevents ETEC adhesion in pigs [77] and a MUC13 isoform lacking the glycosylated extracellular domain is associated with an increased susceptibility to ETEC [78]. However, some evidence has been published to suggest that, rather than MUC13, it is a neighboring gene region that is involved in the reported ETEC susceptibility [79]. In a 3D villi model with Caco-2 cells, MUC17 reduces infection with Salmonella typhimurium and MUC17 knockdown disrupts tight junction formation and leads to increased Salmonella invasion [80]. Together, these data show that mucins can prevent bacterial invasion through barrier function. In addition, and homologous to classical (immune) receptors, the mucin extracellular domain binds bacterial components, which can lead to phosphorylation of the intracellular tail and activation of signaling pathways.

\section{Contribution of Mucins to Cell Proliferation and}

Apoptosis during Bacterial Infection

Loss of mucosal barrier function and an increase in microbiota-epithelial interactions are typical features of inflammatory bowel diseases such as Crohn's disease and ulcerative colitis. Human polymorphisms in MUC3, MUC4, and MUC13 genes have been linked to Crohn's disease and ulcerative colitis, respectively, suggesting a mucin-specific effect $[81,82]$. However, these studies were small case control studies prone to error and therefore should be repeated with larger cohorts. Linking mucins, inflammation, and colitis, mucins are involved in the regulation of apoptosis and cell proliferation in different regions of the gastrointestinal tract. A MUC13 knockout mouse displays increased intestinal inflammation in the mouse colitis model with dextran sulfate [83]. This study nicely uncovers a role for MUC13 in inhibiting apoptosis, as the increased intestinal inflammation observed in the MUC13 knockout mice is most likely caused by increased apoptosis of intestinal epithelial cells. Besides inhibition of apoptosis, MUC13 can influence cell proliferation in the stomach. While MUC13 is normally not expressed in the stomach, it is rapidly upregulated in the stomach of mice infected with the zoonotic bacterium Helicobacter heilmannii [84]. This MUC13 upregulation is associated with the development of gastric cancer. $H$. heilmannii also leads to upregulation of MUC4 and the mucin-like protein DMBT1 in the stomach, and both proteins are considered to be metaplastic markers [84]. Contrary to MUC13 knockout mice, MUC4 knockout mice are less susceptible to the induction of colitis, show reduced infiltration of inflammatory cells, and reduced inflammation-induced carcinogenesis in the colon [85]. Because MUC2 and MUC3 were found to be upregulated in MUC4 knockout mice, it remains to be investigated if the described phenotypes are the direct result of a lack of MUC4 or indirectly caused by the upregulation of other mucins.

Current knowledge indicates that transmembrane mucins play a central role in mucosal maintenance by acting at different levels. As described above, the glycosylated extracellular domains provide barrier function against invasive pathogens and can function as bacterial receptors. In addition, damage of the epithelial barrier may lead to excessive shedding of mucin extracellular domains and subsequent activation of pathways linking to cell proliferation and apoptosis. Therefore, mucins could be sensing both bacteria and damage at the epithelial interface. The next challenge will be to separate barrier, receptor, and signaling functions and to determine the contributions of individual transmembrane mucins to mucosal maintenance and damage control. Transmembrane mucins are expressed on different cell types, including immune cells (see below), and the aforementioned studies have mostly been performed with global knockout mice. Future studies would therefore greatly benefit from the use of tissue-specific knockout mice in order to distinguish contributions of epithelial and immune cell transmembrane mucins.

\section{Regulation of Inflammatory Responses by Transmembrane Mucins}

The soluble mucus layer in the intestinal tract is continuously replaced by newly synthesized mucus. The expression of the secreted mucins MUC2, MUC5AC, MUC5B, and MUC6 is regulated at the transcriptional level by proinflammatory cytokines (IL-1 $\beta$, IL-6, TNF $\alpha$ ), pleiotropic cytokines (IL-4, IL-13, IL-9), and bacterial LPS [86]. While soluble mucins clearly play an important role in maintaining barrier function during invasion by mucosal pathogens, the role of transmembrane mucins in inflammatory responses is less clearly defined because of their diverse functions.

Transmembrane mucins are selectively regulated during inflammation but also regulate inflammatory re-
288

J Innate Immun 2017;9:281-299 DOI: $10.1159 / 000453594$ van Putten/Strijbis 
sponses themselves. A few studies, mostly performed with cancer cells, have reported regulation of transmembrane mucin expression by proinflammatory cytokines. IL- 6 and IFN- $\gamma$ induce STAT 3 and STAT1 binding to the MUC1 promoter and slightly increase MUC1 expression [87]. IL-6 increases expression of MUC13 in colon cancer cells via activation of the JAK2/STAT5 signaling pathway [88]. TNF- $\alpha$ and IFN- $\gamma$ stimulate the expression of transmembrane mucin MUC16 in breast, endometrial and ovarian cancers through an NF- $\kappa B$ response element in the MUC16 promoter [89]. During pulmonary disease, neutrophil elastase increases the expression of MUC4, possibly to activate epithelial repair mechanisms [90]. The anti-inflammatory cytokine TGF- $\beta$ prevents cleavage of the MUC4 SEA domain and directs MUC4 for proteosomal degradation [91]. During inflammatory bowel disease, MUC12 is upregulated by TNF- $\alpha$ and TGF- $\beta$ [81].

A direct comparison of transmembrane mucin-specific effects on inflammation was performed using mouse gastric and intestinal epithelial cell lines and mouse gastric and intestinal tissue ex vivo. Cells with different levels of MUC expression were stimulated with TNF- $\alpha$, NOD1 or TLR ligands, or exposed to H. pylori, and NF- $\kappa \mathrm{B}$ activation and IL- 8 production were measured. Knockdown of MUC1 increased the induced NF- $\kappa B$ activation and IL-8 production in stomach epithelial cells, while the reverse effect was observed for knockdown of MUC13 in intestinal epithelial cells [51]. The authors concluded that, when MUC1 is present, a general anti-inflammatory effect is observed, while expression of MUC13 results in the upregulation proinflammatory pathways. Several studies demonstrate a direct interaction of MUC1 with different players of the NF- $\kappa B$ pathway. During H. pylori infection of the stomach, the MUC1 intracellular tail interacts with IKK $\gamma$ and inhibits I $\mathrm{KB} \alpha$ phosphorylation, thereby blocking NF- $\kappa \mathrm{B}$ activation and IL-8 production in response to $H$. pylori [92]. After stimulation with TNF- $\alpha$, MUC1 associates with the TNF-R1 complex, resulting in the recruitment of TAK1 kinase and phosphorylation of IKK $\beta$ [93]. Contrary to healthy epithelial tissues, a proinflammatory effect of MUC1 on the NF- $\kappa B$ pathway was reported for tumor cells. In mouse and human cancer cell lines, a direct interaction of MUC1 with the NF- $\kappa \mathrm{B}$ subunit p65 was shown for the cytoplasmic domain of MUC1 [94] and for full-length MUC1, and this interaction was dependent on the length of the extracellular mucin domain [95]. In these cancer cells, the MUC1p65 interaction has proinflammatory effects as it results in the upregulation of IL-6 and TNFa transcription [95].

Transmembrane Mucins
We conclude that MUC1 directly interacts with components of the NF- $\kappa$ B pathway and modulates its activity in a cell-dependent manner.

MUC1 can also directly interact with Toll-like receptors and thereby modulate TLR responses. Binding of MUC1 to TLR5 in airway epithelial cells prevents the recruitment of MyD88 to the intracellular tail, thereby inhibiting signaling and NF- $\mathrm{KB}$ activation $[47,96]$. MUC1 also inhibits signaling through TLR3 [97] and dampens TLR2 and TLR5 signaling in ocular epithelial cells [98]. MUC1 is part of a feedback loop that downregulates TLR2-induced IL- 8 and TNF- $\alpha$ production after infection with nontypeable Haemophilus influenzae in airway epithelial cells [99]. The immunomodulatory effect of MUC1 on TLR responses could act at several levels. Firstly, the glycosylated extracellular domain of MUC1 could shield the TLR extracellular domain and reduce TLR-ligand interactions. Secondly, formation of a MUC1-TLR receptor complex could impact ligand binding and recognition. Thirdly, the direct interaction between MUC1 and TLR could prevent the binding of MyD88 to the TLR intracellular tail. Fourthly, the intracellular tail of MUC1 could act downstream by interacting with components of the NF- $\mathrm{KB}$ pathway and modulate its activity.

\section{Expression and Function in Immune Cells}

In addition to healthy epithelial cells and cancer cells, transmembrane mucins are expressed by various immune cells $[25,100]$. Limited data are available on the function of transmembrane mucins in these cells, but it seems likely that, as in epithelial cells, they have immunomodulatory and signaling functions. In line with its anti-inflammatory effects in healthy epithelial cells, MUC1 dampens phagocytosis by macrophages [101] and decreases secretion of TNF- $\alpha$ and IFN- $\gamma$ after stimulation with LPS or flagellin in dendritic cells (DCs). The importance of MUC1-mediated immune dampening is illustrated by the continuous activation of DCs after knocking out MUC1 [102]. As discussed above, MUC1 plays a crucial role in defense against enteropathogenic bacteria. MUC1 knockout mice therefore develop a severe gastritis after $H$. $p y$ lori infection $[65,66]$. Surprisingly, the use of bone marrow chimeric mice demonstrated that this gastritis is not dependent on epithelial MUC1, but rather on MUC1 expressed by macrophages [103]. The MUC1 knockout macrophages produce high levels of IL-1 $\beta$ and IL-18 in response to $H$. pylori [103]. In wildtype macrophages MUC1 negatively regulates the phosphorylation of IRAK4 and reduces NF- $\kappa \mathrm{B}$ and NLRP3 inflammasome activation. The MUC1-mediated regulation of NLRP3 inflam-

J Innate Immun 2017;9:281-299 DOI: $10.1159 / 000453594$ 
masome activity is highly specific, as NLRP1b, NLRC4, and AIM2 inflammasomes are not affected by the absence of MUC1 [100]. In addition to macrophages and DCs, MUC1 is expressed on activated T cells and may be involved in release of $\mathrm{T}$ cell-lymph node interactions to move to tissue locations [104]. It is tempting to speculate that similar to other immune cells, T-cell activation might also be regulated by MUC1. The underlying mechanisms of the dampening effect of MUC1 in macrophages and DCs remain to be elucidated, but are most likely dependent on the dense glycan network of the extracellular domain and the interactions of the cytoplasmic domain with the NF- $\kappa B$ pathway. Little is known about the expression of other transmembrane mucins on immune cells. MUC13 is expressed on hemopoietic cells [25], but its function in these cells remains to be established. Expression of other transmembrane mucins in immune cells has so far not been reported in the literature. Mucins could have a major impact on immune cell migration and homing, as mucin glycans can bind to E-selectin and the MUC1 peptide backbone interacts with intracellular adhesion molecule 1 (ICAM-1) expressed on endothelial cells $[105,106]$ (discussed below). However, these interactions were demonstrated for cancer cells and their contributions to immune cell migration remain to be studied.

\section{Contribution of Mucins to Carcinogenesis and Metastasis}

Transmembrane mucins are overexpressed or aberrantly expressed in several different adenocarcinomas, including colon, breast, pancreas, and ovarian cancer, and their overexpression is associated with a poor prognosis. However, a causative relationship between mucin overexpression and carcinogenesis has not been established conclusively. Overexpression of MUC1 is associated with invasive and metastatic tumors of the colon, pancreas, gall bladder, and oral epithelium [4]. Mammary tumors of MUC1 knockout mice grow slower and have a reduced ability to metastasize [107]. In the early steps of pancreatic carcinogenesis, changes in DNA methylation and histone acetylation lead to the upregulation of MUC4 $[108,109]$. MUC4 knockout mice develop less cancer in a combined inflammation-induced carcinogenesis model [85], demonstrating that MUC4 contributes to carcinogenesis under inflammatory conditions. In healthy colon, MUC13 localizes to the apical side of epithelial cells, but MUC13 is overexpressed in colon cancer and polarized localization is lost [110]. MUC17 is also upregulated in pancreatic cancer and genetic variations in MUC17 are associated with endometriosis [111]. In addition to mucin overexpression, changes in mucin glycosylation status are thought to significantly contribute to their carcinogenic properties. Glycosyltransferases are differentially expressed in cancer cells resulting in aberrant, often reduced, glycosylation of surface glycoproteins [112]. Mucins expressed by healthy tissue are differentially glycosylated compared to mucins expressed by tumor cells derived from the same tissue $[10,113]$, and the density of mucin glycosylation can also vary between normal tissue and cancer cells [114]. The differentially glycosylated mucins that are expressed by tumors can be used as cancer markers. One interesting characteristic of metastatic carcinoma is the excessive shedding of mucin extracellular domains [16]; mucin glycoproteins can be detected in serum by tumor-associated antigen-specific antibodies that detect mucin-specific and glycosylation-specific epitopes. Increased serum levels of mucin tumor-associated antigens correlate with an increasing tumor burden and poor prognosis in breast cancer (CA15-3; MUC1), colorectal and pancreatic adenocarcinomas (CA19-9; MUC1), and ovarian carcinoma (CA125; MUC16) [115118]. It is unclear if excessive shedding of mucin extracellular domains is the cause or consequence of carcinogenesis and whether the shedding initiates procarcinogenic signaling through phosphorylation and activation of the intracellular domain. In addition, shed extracellular domains may have more distant effects, for example by interfering with immune cell homing by blocking E-selectin on endothelial cells (see below).

So why are transmembrane mucins important oncogenic proteins? The available data suggest that transmembrane mucins can contribute to carcinogenesis both via their glycosylated extracellular domain that may protect cancer cells in harmful conditions and via the intracellular domain that links to pathways that regulate cell differentiation, apoptosis, and inflammation. In addition, cancer cells seem to employ transmembrane mucins to regulate detachment and reattachment during metastasis. In healthy epithelial cells, transmembrane mucins are expressed on the apical membrane. In cancer cells, polarized expression of transmembrane mucins is lost resulting in the disruption of tight junctions and dissociation of the cancer cells from the adjacent cells [119] (Fig. 1d). The disruption of tight junctions by transmembrane mucin overexpression could be directly caused by the presence of the glycosylated extracellular domain, as was hypothesized for MUC13 [119]. Because the rod-like glycosylated extracellular domain extends far from the plasma 
membrane, it may disrupt tight junctions by preventing interactions between surface receptors and their ligands on adjacent cells (Fig. 4). Alternatively or simultaneously, activation of the intracellular domain can also influence cell-cell interactions as has been described for MUC1 (Fig. 4; see below).

\section{Regulation of Cell-Cell Interactions by the \\ Extracellular Domain}

The carcinogenic processes of cell invasion and metastasis include release of cells from the site of origin, movement through normal stromal elements and the lymphatic system, and establishment of a colony at the metastatic site. The transition through all these different phases requires cancer cells to display adhesive and antiadhesive functions that can both be mediated by transmembrane mucins. This is nicely demonstrated by E-selectin-mediated adhesion of tumor cells to endothelial cells. E-selectin is normally expressed on the surface of activated endothelial cells during inflammation and contains a C-type lectin domain that interacts with sialylated carbohydrates found in high abundance on immune cells [120]. Similar to immune cells, cancer cells also express these E-selectin ligands and induce tumor cell rolling on the endothelium. After rolling is initiated, integrins are upregulated and a strong interaction with endothelial ICAM-type proteins facilitates extravasation and metastasis. MUC1 plays a dual role in this process of cell-cell adhesion, as is illustrated by the different blocking and adhesive properties of full-length MUC1. Overexpression of MUC1 containing the glycosylated mucin domain in pancreatic tumor cells specifically blocks recognition of tumor-associated ligands by E-selectin but not to P-selectin, another cell adhesion molecule that is also involved in tumor metastasis [106]. The blocking effect of MUC1 may be explained by a stoichiometric effect of low-affinity interactions between E-selectin and mucin glycans or direct barrier formation. Barrier formation by MUC1 can for example prevent integrin-mediated interaction with extracellular matrix components like ICAM-1. In addition to interactions between cell-bound MUC1 and E-selectin on endothelial cells, shed MUC1 extracellular domain also interacts with E-selectin. It was shown that shed MUC1 from tumor cells inhibits leukocyte adhesion to the endothelium, thereby dampening immune responses [121].

Interestingly, the dense network of glycosylated MUC1 can be "opened" by external factors like antibodies and lectins. For instance, incubation with anti-MUC1 antibodies leads to MUC1 clustering and restores adhesion by exposure of surface receptors [122]. In breast carci-

Transmembrane Mucins

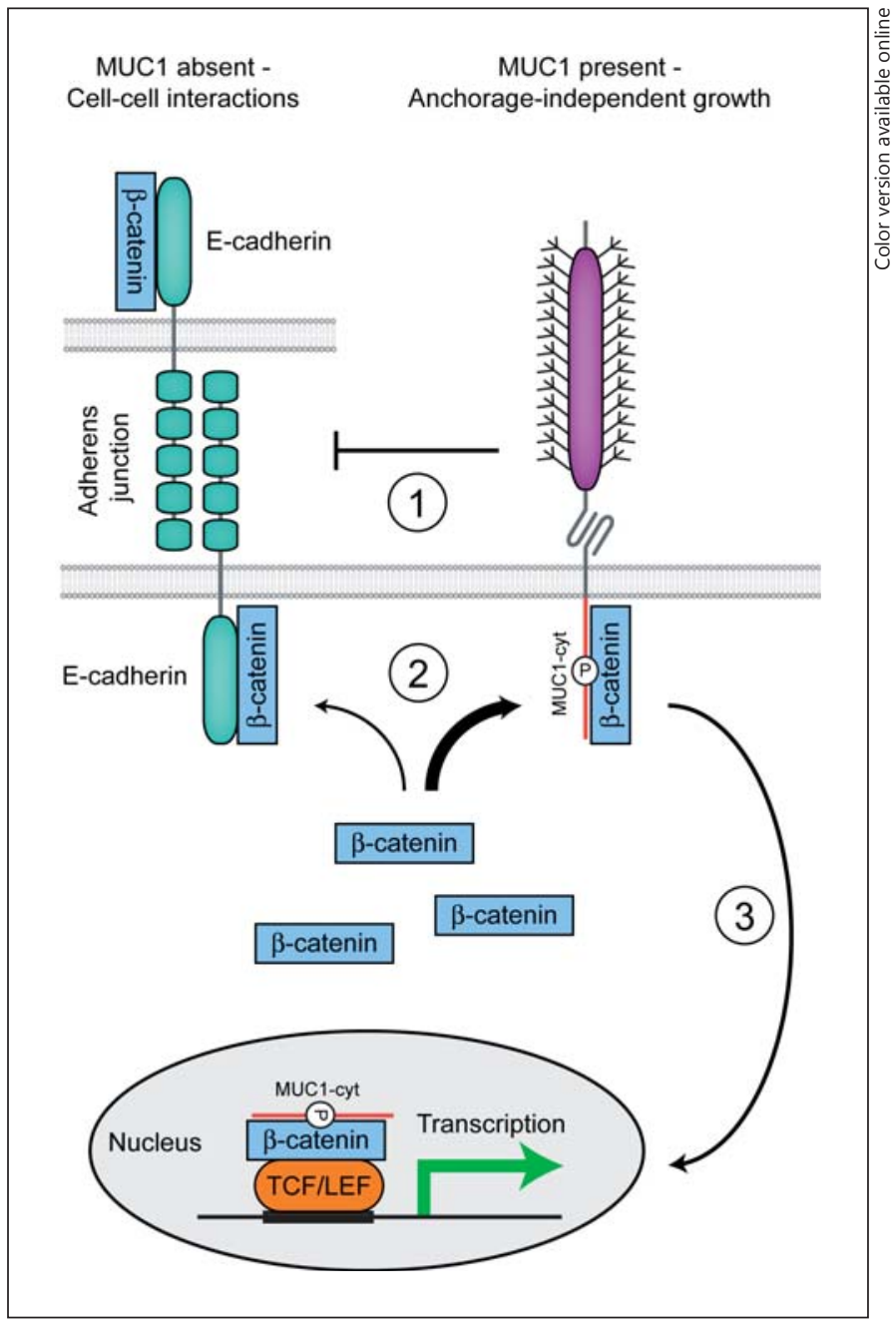

Fig. 4. Regulation of cell-cell contact by MUC1. In epithelial cells in the absence of MUC1, $\beta$-catenin associates with E-cadherin at the plasma membrane. The $\beta$-catenin-E-cadherin complex connects to the actin cytoskeleton and enables adherens junction formation with neighboring cells. Overexpression and/or aberrant localization of MUC1 lead to the loss of cell-cell contact and induces anchorage-independent growth. MUC1 impacts cell-cell interactions in multiple ways. (1) The glycosylated extracellular domain of MUC1 directly disturbs E-cadherin interactions between adjacent cells. (2) $\beta$-Catenin preferentially binds to the phosphorylated intracellular tail of MUC1. Dissociation of the $\beta$-catenin-Ecadherin complex leads to the loss of adherens junctions. (3) A complex of $\beta$-catenin and the MUC1 cytoplasmic tail can traffic to the nucleus, bind to the Wnt signaling transcription factor TCF/ $\mathrm{LEF}$, and modulate the transcription of genes involved in cell proliferation and differentiation.

noma cells that grow in suspension, capping of MUC1 with antibodies reverses cells to adherent growth [122]. MUC1 clustering can also be achieved by interaction with galectin-3, a galactose-binding lectin, the serum levels of

J Innate Immun 2017;9:281-299 DOI: $10.1159 / 000453594$ 
which are increased in cancer patients. Galectin-3 binds Thomsen-Friedenreich disaccharides on cancer-associated MUC1, induces MUC1 polarization, and opens up the protective MUC1 shield [123]. This leads to exposure of smaller cell surface adhesion molecules like CD44 and E-selectin ligands and increases interactions with endothelial ligands [124]. In addition, galectin-3 binding to MUC1 sugars mediates tumor cell-cell aggregation and increased survival [125]. By increasing cancer cell-endothelial cell adhesion and cell-cell aggregation, circulating galectin-3 promotes metastasis. Peanut agglutinin, another galactose-binding lectin that can be detected in the circulation of healthy volunteers after the consumption of peanuts [126], has similar effects on MUC1 clustering, cell-cell aggregation, and cancer metastasis [127]. Therefore, different types of lectins and mucin-binding antibodies can impact cell adhesion through interactions with transmembrane mucins.

Shielding of receptors by MUC1 barrier formation can inhibit receptor-ligand interactions, but the extracellular domain of MUC1 itself was also shown to function as "ligand" for different receptor/adhesion proteins. The MUC1 tandem repeat domain directly interacts with ICAM-1 [106, 128]. Ligation of MUC1 and ICAM-1 induces a calcium signal in the MUC1-expressing cell that stimulates migration [129]. In vitro, overexpression of full-length MUC1 increases the invasiveness of tumor cells through Matrigel due to a decreased ability to bind type I collagen, type IV collagen, and laminin [130]. On the other hand, overexpression of MUC1 reduces lymphatic vessel invasion in a mouse model while deletion of the glycosylated MUC1 tandem repeat region restores invasive properties [130]. Another example of a MUC1 interaction partner is the sialic acid-binding lectin receptor Siglec-4a. The MUC1-Siglec-4a interaction contributes to invasion during pancreatic cancer progression [131]. In addition to regulating cell-cell interactions and metastasis, the dense glycan layer provided by extracellular domains of transmembrane mucins protects tumor cells in adverse environments [4]. This direct effect of the glycosylated mucins is illustrated by overexpression of MUC1 that confers resistance to genotoxic anticancer agents [132] and protects melanoma cells from lysis by cytotoxic T cells [105].

Transmembrane mucins other than MUC1 also play a role in cell-cell adhesion and metastasis, but these interactions have not been studied extensively. For example, MUC4 overexpression leads to cell dissociation and this phenotype depends on mucin repeats in the extracellular domain [133]. Overexpression of MUC13 in colon and ovarian cancer results in reduced cell-cell adhesion and increased motility, while silencing of MUC13 decreased these tumorigenic features $[88,134]$. MUC16 interacts with mesothelin and this interaction leads to expression of a metalloprotease and increased motility and metastasis of pancreatic cancer cells [135].

\section{Regulation of Cell-Cell Interactions by the Intracellular Domain}

In addition to transmembrane mucin ectodomains, intracellular domains contribute to carcinogenesis. $\beta$-Catenin is a member of the WNT signaling cascade that normally forms a complex with cell-surface adhesion molecules such as E-cadherin, resulting in stable cell-cell interactions between epithelial cells (Fig. 4). In cancer cells where polarized expression of transmembrane mucins is lost, the MUC1 cytoplasmic tail competes for binding to $\beta$-catenin and thus decreases cell-cell adhesions through E-cadherin [50]. The MUC1- $\beta$ catenin interaction is essential for anchorage-independent growth of tumor cells and mediated by a $\beta$-cateninbinding motif in the MUC1 cytoplasmic tail (50SAGNGGSSL-59) [136]. Phosphorylation of the MUC1 cytoplasmic tail regulates its interaction with $\beta$-catenin and MUC1 tail phosphorylation correlates with changes in cell-cell adhesion $[136,137]$. Several kinases have been implicated in phosphorylation of MUC1 with different impacts on the interaction with $\beta$-catenin. Phosphorylation by c-SRC tyrosine kinase and protein kinase $C \delta$, $\mathrm{PKC} \delta$, increase interaction, while phosphorylation by glycogen synthase kinase- $3 \beta$, GSK3 $\beta$, negatively regulates the interaction $[49,138,139]$. A MUC1 Y46F tyrosine mutant is attenuated in binding $\beta$-catenin and cells expressing this mutant MUC1 are no longer able to support anchorage-independent growth [140]. Together, these data show that the intracellular domain of MUC1 plays an important role in the regulation of cell-cell interactions and thereby can contribute to carcinogenesis and metastasis.

Modulation of cell-cell interactions through the E-cadherin/ $\beta$-catenin pathway could be a more general feature of transmembrane mucins, as MUC16 was also described to modulate this pathway. MUC16 is cleaved in the ectodomain close to the plasma membrane, resulting in a $17-\mathrm{kDa}$ C-terminal fragment that contains the transmembrane domain [26]. This C-terminal MUC16 fragment interacts with $\mathrm{E}$-cadherin and alters $\beta$-catenin signaling [141]. In this way, MUC16 promotes the formation of multicellular aggregates that facilitate migration and metastasis. van Putten/Strijbis 
Nuclear Localization of Transmembrane Mucins and

Transcriptional Modulation

Somewhat counterintuitively, transmembrane mucins have been reported to also localize to the nucleus. Complexes of the MUC1 cytoplasmic tail with transcription factors were found in the nucleus and the association with MUC1 was shown to modulate transcription. The aforementioned MUC1- $\beta$-catenin complex can traffic to the nucleus and regulates genes involved in cell proliferation and differentiation [142]. Platelet-derived growth factor- $\beta$, PDGFR $\beta$, induces tyrosine phosphorylation of the MUC1 tail and increases nuclear localization of the MUC1- $\beta$-catenin complex [143]. Through its interaction with $\beta$-catenin and also p110 catenin, MUC1 influences WNT signaling and the transcription of cyclinD1 [144] (Fig. 4). These events contribute to the invasiveness of pancreatic adenocarcinoma cells [143], and MUC1 and nuclear $\beta$-catenin are overexpressed at the invasion front of colorectal carcinomas [145]. In addition to $\beta$-catenin, interactions of the (phosphorylated) MUC1 tail with the transcription factors p53 [48], KLF-4 [146], and estrogen receptor- $\alpha$ DNA binding protein have been described [147], but these interactions remain to be confirmed by other groups. In general, formation of a MUC1-transcription factor complex could result in nuclear localization and transcriptional regulation. The function of the MUC1 tail might be to increase transcription factor stability and activity and, therefore, the phosphorylated MUC1 tail could function as a general transcriptional modulator. It is tempting to speculate that certain phosphorylation events could lead to complex formation with specific partners. Unfortunately, many of the aforementioned studies make use of overexpression of the MUC1 tail without the extracellular domain and, therefore, may overestimate the impact of MUC1 on the transcriptional outcome. It is also unclear at this point through which pathway the MUC1 cytoplasmic tail would be released from the plasma membrane as this process does not seem to be dependent on $\gamma$-secretase [53]. However, full-length glycosylated MUC1 was also suggested to localize to the nucleus [95], but it remains to be determined how a fulllength glycosylated mucin could traffic to the nucleus. Nuclear localization of transmembrane mucins and their impact on transcription needs to be addressed with currently available tools, including inducible expression, genetic knockouts, and regulated release of the cytoplasmic tail.

MUC13 and MUC16 were also reported to localize to the nucleus and regulate transcription. Nuclear localization of MUC13 was observed in colon cancer epithelial

Transmembrane Mucins cells by immunohistochemistry and associated with metastatic progression [110]. MUC13 expression leads to transcriptional modulation of the genes involved in apoptosis and cell proliferation (see below), but it is unclear if this effect is a result of signaling activity or directly caused by nuclear localization [88]. Cleavage of MUC16 results in a C-terminal fragment containing the transmembrane domain and an intracellular tail that can traffic to the nucleus and bind chromatin [26]. Through interaction with JAK2, this MUC16 fragment upregulates the expression of stem cell genes LMO2 and NANOG in pancreatic cancer cells [148]. The C-terminal MUC16 fragment also increases motility and metastatic properties of pancreatic cancer cells in vivo and increases resistance to chemotherapy [148]. Although the exact mechanisms of cleavage and trafficking remain to be established, these studies convincingly demonstrate that full-length transmembrane mucins or cleaved fragments can traffic to the nucleus and directly impact transcription.

\section{Inhibition of Apoptosis and Impact on Cell Proliferation}

As discussed above, transmembrane mucins are involved in mucosal maintenance and the regulation of cell proliferation and apoptosis in healthy mucosal tissues. Anoikis is a specialized apoptotic process that is induced in healthy epithelial cells after the loss of cell adhesion. Cancer cells need to overcome anoikis stimuli to be able to metastasize. The glycosylated extracellular domain of MUC1 inhibits anoikis by shielding death receptors such as the Fas ligand on the cell surface [125]. MUC1 enhances carcinogenesis by activation of the Akt pathway that regulates cell proliferation and migration $[149,150]$. Activation of the MUC1 cytoplasmic tail leads to the phosphorylation of Akt and Bad, resulting in the upregulation of mitochondrial Bcl-Xl and inhibition of apoptosis [132, 151]. MUC13 prevents apoptosis in colon epithelial cells in an in vivo model [83]. Through activation of signaling pathways and/or nuclear localization, MUC13 modulates the expression of genes involved in differentiation and apoptosis, including telomerase reverse transcriptase, sonic hedgehog, B cell lymphoma murine-like site 1, and TATA-like transcription factor 1, HER2, and P-ERK [88]. These findings indicate that, in line with their role in mucosal maintenance, both MUC1 and MUC13 modulate pathways that regulate cell differentiation and apoptosis in cancer. MUC16 is not expressed in nonneoplastic breast tissue, but is overexpressed in breast cancer [152]. The C-terminal fragment of MUC16 increases cell growth by interaction with JAK2 and phosphorylation of STAT3,

J Innate Immun 2017;9:281-299 DOI: $10.1159 / 000453594$ 
and decreases apoptosis through the TRAIL (tumor necrosis factor-related apoptosis-inducing ligand)-mediated extrinsic apoptotic pathway $[152,153]$.

Human EGF receptors (ERBB receptors) are oncoproteins that are overexpressed in breast, ovarian, stomach, and uterine carcinomas. This overexpression is associated with increased disease recurrence and poor prognosis. ERBB2 activation promotes cell proliferation and inhibits apoptosis. Mucin EGF domains were shown to interact with members of the ERBB family. For example, the MUC4 EGF domain interacts with ERBB2 receptor tyrosine kinase (also known as HER2), leading to phosphorylation of ERBB2 and induction of cellular differentiation signals through the cyclin-dependent kinase inhibitor KIP1 (also known as p27) [34-36]. MUC4 antagonizes the association of ERBB2 with ERBB3-neuregulin, which normally signals cell proliferation through MAPK pathways [37]. Upregulation of MUC4 inhibited apoptosis in a melanoma cell line. Therefore, the MUC4-ERBB2 interaction functions as an antiapoptotic signal that contributes to the survival of epithelial cells [38].

While MUC1 does not contain a typical EGF domain, it has been shown to interact with ERBB1 and ERBB2 in breast cancer cells $[154,155]$ and all 4 ERBB receptors in mammary glands [156]. Similar to the stabilizing effect of MUC1 on transcription factors, MUC1 stabilizes ERBB1 by complex formation and enhances ERBB1 signaling after ligand stimulation [157]. The MUC1/ERBB1 interaction regulates ERK1/2 phosphorylation and activation of the MAPK pathway $[156,158]$, a pathway that is often disrupted in cancers. Mucin-ERBB interactions therefore stimulate signaling related to growth, motility, differentiation, and inflammation [36, 159]. Phosphorylated MUC1, activated growth factor receptors, and integrins are also functionally linked as all 3 can interact with the growth factor receptor-bound protein 2 (Grb2), an adaptor protein that plays a central role in cell proliferation [160]. In healthy tissues, transmembrane mucins function in mucosal maintenance by barrier formation, monitoring luminal events, and initiating differentiation or apoptosis when necessary. Cancer cells seem to exploit this central role of transmembrane mucins and highjack mucin signaling for prolonged survival.

\section{Closing Remarks}

Transmembrane mucins are essential barrier proteins at the mucosal surface and have the capacity to modulate inflammation, differentiation, and apoptosis. Trans- membrane mucins can be considered as outside-to-inside signaling receptors with highly specific functions that monitor the mucosal lumen with the extracellular domain and initiate epithelial responses by activation of the intracellular domain.

At the mucosal surface, transmembrane mucins sense bacterial ligands or mucosal damage and relay this information by activation of the appropriate immunomodulatory or repair pathways. Barrier formation prevents access by pathogens and prevents the early activation of immune receptors. In cancer cells, transmembrane mucins contribute to cell survival and metastasis through the regulation of cell-cell interactions and aberrant regulation of pathways involved in cell proliferation and apoptosis.

Most of our knowledge on transmembrane mucins comes from the cancer field and the study of MUC1. Through the use of primary cells, tissues, and animal models, and by extending our studies to other transmembrane mucins, we are now slowly starting to appreciate their important function at the mucosal surface. The original function of transmembrane mucins was most likely defense and repair at mucosal surfaces, but cancer cells have highjacked these abilities to increase the cell protection, survival, and metastasis of growing tumors. At the mucosal surface during inflammation, bacterial ligands bind the extracellular mucin domain, both the cell-bound receptor and the shed form that functions as a decoy receptor. Epithelial damage may induce shedding of the extracellular domain and the initiation of pathways involved in proliferation and apoptosis. During carcinogenesis, the loss of apical expression of glycosylated mucins leads to cell detachment and mucin interactions with endothelial E-selectin can contribute to metastasis. In addition, the interaction of shed mucins with E-selectin can prevent the homing of immune cells during carcinogenesis. The high mucin serum levels associated with adenocarcinomas suggest that mucin shedding contributes to carcinogenesis, maybe because it leads to continuous activation of the cytoplasmic tail and intracellular pathways that contribute to cell survival. A few examples suggest that bacterial binding of the extracellular domain leads to phosphorylation of the intracellular mucin tail. In cancer cells, the intracellular tail is also phosphorylated and can traffic to the nucleus, interact with transcription factors, and influence transcription. In epithelial cells, the intracellular tail can modulate immune responses such as the NF- $\kappa B$ pathway and IL-8 production. Nuclear localization of mucin tails during mucosal maintenance or inflammation is largely unexplored. The next frontiers in the field are to understand the mechanisms of transmem-
294

J Innate Immun 2017;9:281-299 DOI: $10.1159 / 000453594$ van Putten/Strijbis 
brane mucin activation by binding/shedding of the extracellular domain and the intracellular signaling pathways that link to the different transmembrane mucins. Because of their essential roles at the mucosal interface, inflammation and carcinogenesis transmembrane mucins warrant a more extensive exploration of their biological functions and their potential as diagnostic and therapeutic targets in inflammatory diseases and cancer.

\section{Acknowledgements}

We thank Gunnar C. Hansson and Marcel R. de Zoete for critically reading the manuscript. K.S. is funded by a Marie Curie International Incoming Fellowship (IIF).

\section{References}

1 Johansson ME, Phillipson M, Petersson J, Velcich A, Holm L, Hansson GC: The inner of the two Muc2 mucin-dependent mucus layers in colon is devoid of bacteria. Proc Natl Acad Sci USA 2008;105:15064-15069.

$\checkmark 2$ Li H, Limenitakis JP, Ganal SC, Macpherson AJ: Penetrability of the inner mucus layer: who is out there? EMBO Rep 2015;16:127129.

-3 Forstner JF: Intestinal mucins in health and disease. Digestion 1978;17:234-263.

4 Hollingsworth MA, Swanson BJ: Mucins in cancer: protection and control of the cell surface. Nat Rev Cancer 2004;4:45-60.

$\checkmark 5$ Pickard JM, Chervonsky AV: Intestinal fucose as a mediator of host-microbe symbiosis. J Immunol 2015;194:5588-5593.

-6 Burdick MD, Harris A, Reid CJ, Iwamura T, Hollingsworth MA: Oligosaccharides expressed on MUC1 produced by pancreatic and colon tumor cell lines. J Biol Chem 1997; 272:24198-24202.

7 Hilkens J, Buijs F, Ligtenberg M: Complexity of MAM-6, an epithelial sialomucin associated with carcinomas. Cancer Res 1989;49: 786-793.

-8 Gendler SJ, Lancaster CA, Taylor-Papadimitriou J, Duhig T, Peat N, Burchell J, Pemberton L, Lalani EN, Wilson D: Molecular cloning and expression of human tumor-associated polymorphic epithelial mucin. J Biol Chem 1990;265:15286-15293.

$\checkmark 9$ Ligtenberg MJ, Vos HL, Gennissen AM, Hilkens J: Episialin, a carcinoma-associated mucin, is generated by a polymorphic gene encoding splice variants with alternative amino termini. J Biol Chem 1990;265:5573-5578.

-10 Lan MS, Batra SK, Qi WN, Metzgar RS, Hollingsworth MA: Cloning and sequencing of a human pancreatic tumor mucin cDNA. J Biol Chem 1990;265:15294-15299.

11 Bork P, Patthy L: The SEA module: a new extracellular domain associated with O-glycosylation. Protein Sci 1995;4:1421-1425.

-12 Levitin F, Stern O, Weiss M, Gil-Henn C, Ziv R, Prokocimer Z, Smorodinsky NI, Rubinstein DB, Wreschner DH: The MUC1 SEA module is a self-cleaving domain. J Biol Chem 2005;280:33374-33386.
13 Macao B, Johansson DG, Hansson GC, Hard $\mathrm{T}$ : Autoproteolysis coupled to protein folding in the SEA domain of the membrane-bound MUC1 mucin. Nat Struct Mol Biol 2006;13: 71-76.

14 Palmai-Pallag T, Khodabukus N, Kinarsky L, Leir SH, Sherman S, Hollingsworth MA, Harris A: The role of the SEA (sea urchin sperm protein, enterokinase and agrin) module in cleavage of membrane-tethered mucins. FEBS J 2005;272:2901-2911.

15 Pelaseyed T, Zach M, Petersson AC, Svensson F, Johansson DG, Hansson GC: Unfolding dynamics of the mucin SEA domain probed by force spectroscopy suggest that it acts as a cell-protective device. FEBS J 2013;280:14911501.

16 Smorodinsky N, Weiss M, Hartmann ML, Baruch A, Harness E, Yaakobovitz M, Keydar I, Wreschner DH: Detection of a secreted MUC1/SEC protein by MUC1 isoform specific monoclonal antibodies. Biochem Biophys Res Commun 1996;228:115-121.

17 Shirazi T, Longman RJ, Corfield AP, Probert CS: Mucins and inflammatory bowel disease. Postgrad Med J 2000;76:473-478.

18 Buisine MP, Desreumaux P, Leteurtre E, Copin MC, Colombel JF, Porchet N, Aubert JP: Mucin gene expression in intestinal epithelial cells in Crohn's disease. Gut 2001;49:544551.

19 Khatri IA, Ho C, Specian RD, Forstner JF: Characteristics of rodent intestinal mucin Muc3 and alterations in a mouse model of human cystic fibrosis. Am J Physiol Gastrointest Liver Physiol 2001;280:G1321-G1330.

20 Lillehoj EP, Han F, Kim KC: Mutagenesis of a Gly-Ser cleavage site in MUC1 inhibits ectodomain shedding. Biochem Biophys Res Commun 2003;307:743-749.

21 Parry S, Silverman HS, McDermott K, Willis A, Hollingsworth MA, Harris A: Identification of MUC1 proteolytic cleavage sites in vivo. Biochem Biophys Res Commun 2001; 283:715-720.

22 Soto P, Zhang J, Carraway KL: Enzymatic cleavage as a processing step in the maturation of Muc4/sialomucin complex. J Cell Biochem 2006;97:1267-1274.
23 Lidell ME, Hansson GC: Cleavage in the GDPH sequence of the C-terminal cysteinerich part of the human MUC5AC mucin. Biochem J 2006;399:121-129.

24 Lidell ME, Johansson ME, Hansson GC: An autocatalytic cleavage in the $\mathrm{C}$ terminus of the human MUC2 mucin occurs at the low $\mathrm{pH}$ of the late secretory pathway. J Biol Chem 2003; 278:13944-13951.

25 Williams SJ, Wreschner DH, Tran M, Eyre HJ, Sutherland GR, McGuckin MA: Muc13, a novel human cell surface mucin expressed by epithelial and hemopoietic cells. J Biol Chem 2001;276:18327-18336.

26 Das S, Majhi PD, Al-Mugotir MH, Rachagani S, Sorgen P, Batra SK: Membrane proximal ectodomain cleavage of MUC16 occurs in the acidifying Golgi/post-Golgi compartments. Sci Rep 2015;5:9759.

27 Thathiah A, Blobel CP, Carson DD: Tumor necrosis factor-a converting enzyme/ADAM 17 mediates MUC1 shedding. J Biol Chem 2003;278:3386-3394

28 Thathiah A, Carson DD: MT1-MMP mediates MUC1 shedding independent of TACE/ ADAM17. Biochem J 2004;382:363-373.

29 Blalock TD, Spurr-Michaud SJ, Tisdale AS, Gipson IK: Release of membrane-associated mucins from ocular surface epithelia. Invest Ophthalmol Vis Sci 2008;49:1864-1871.

-30 Vadaie N, Dionne H, Akajagbor DS, Nickerson SR, Krysan DJ, Cullen PJ: Cleavage of the signaling mucin Msb2 by the aspartyl protease Yps1 is required for MAPK activation in yeast. J Cell Biol 2008;181:1073-1081.

-31 Puri S, Kumar R, Chadha S, Tati S, Conti HR, Hube B, Cullen PJ, Edgerton M: Secreted aspartic protease cleavage of Candida albicans Msb2 activates Cek1 MAPK signaling affecting biofilm formation and oropharyngeal candidiasis. PLoS One 2012;7:e46020.

32 Takeyama K, Dabbagh K, Lee HM, Agusti C, Lausier JA, Ueki IF, Grattan KM, Nadel JA: Epidermal growth factor system regulates mucin production in airways. Proc Natl Acad Sci USA 1999;96:3081-3086.

33 Playford RJ: Peptides and gastrointestinal mucosal integrity. Gut 1995;37:595-597. 
- 34 Carraway KL 3rd, Rossi EA, Komatsu M, Price-Schiavi SA, Huang D, Guy PM, Carvajal ME, Fregien N, Carraway CA, Carraway KL: An intramembrane modulator of the ErbB2 receptor tyrosine kinase that potentiates neuregulin signaling. J Biol Chem 1999;274: 5263-5266.

- 35 Funes M, Miller JK, Lai C, Carraway KL 3rd, Sweeney C: The mucin Muc4 potentiates neuregulin signaling by increasing the cell-surface populations of ErbB2 and ErbB3. J Biol Chem 2006;281:19310-19319.

- 36 Jepson S, Komatsu M, Haq B, Arango ME, Huang D, Carraway CA, Carraway KL: Muc4/ sialomucin complex, the intramembrane ErbB2 ligand, induces specific phosphorylation of ErbB2 and enhances expression of p2 $7^{\mathrm{kip}}$, but does not activate mitogen-activated kinase or protein kinaseB/Akt pathways. Oncogene 2002;21:7524-7532.

37 Zhu X, Price-Schiavi SA, Carraway KL: Extracellular regulated kinase (ERK)-dependent regulation of sialomucin complex/rat Muc4 in mammary epithelial cells. Oncogene 2000; 19:4354-4361.

- 38 Komatsu M, Jepson S, Arango ME, Carothers Carraway CA, Carraway KL: Muc4/sialomucin complex, an intramembrane modulator of ErbB2/HER2/Neu, potentiates primary tumor growth and suppresses apoptosis in a xenotransplanted tumor. Oncogene 2001;20: 461-470.

39 Carraway KL, Ramsauer VP, Haq B, Carothers Carraway CA: Cell signaling through membrane mucins. BioEssays 2003;25:66-71.

40 Malmberg EK, Pelaseyed T, Petersson AC, Seidler UE, De Jonge H, Riordan JR, Hansson GC: The C-terminus of the transmembrane mucin MUC17 binds to the scaffold protein PDZK1 that stably localizes it to the enterocyte apical membrane in the small intestine. Biochem J 2008;410:283-289.

41 Lamprecht G, Seidler U: The emerging role of $\mathrm{PDZ}$ adapter proteins for regulation of intestinal ion transport. Am J Physiol Gastrointest Liver Physiol 2006;291:G766-G777.

-42 Pelaseyed T, Hansson GC: CFTR anion channel modulates expression of human transmembrane mucin MUC3 through the PDZ protein GOPC. J Cell Sci 2011;124:30743083.

-43 Pelaseyed T, Gustafsson JK, Gustafsson IJ, Ermund A, Hansson GC: Carbachol-induced MUC17 endocytosis is concomitant with NHE3 internalization and CFTR membrane recruitment in enterocytes. Am J Physiol Cell Physiol 2013;305:C457-C467.

-44 Pelaseyed T, Bergstrom JH, Gustafsson JK, Ermund A, Birchenough GM, Schutte A, van der Post S, Svensson F, Rodriguez-Pineiro AM, Nystrom EE, Wising C, Johansson ME, Hansson GC: The mucus and mucins of the goblet cells and enterocytes provide the first defense line of the gastrointestinal tract and interact with the immune system. Immunol Rev 2014;260:8-20.
5 Wang H, Lillehoj EP, Kim KC: Identification of four sites of stimulated tyrosine phosphorylation in the MUC1 cytoplasmic tail. Biochem Biophys Res Commun 2003;310:341346.

46 Zrihan-Licht S, Baruch A, Elroy-Stein O, Keydar I, Wreschner DH: Tyrosine phosphorylation of the MUC1 breast cancer membrane proteins: cytokine receptor-like molecules. FEBS Lett 1994;356:130-136.

47 Kato K, Lillehoj EP, Park YS, Umehara T, Hoffman NE, Madesh M, Kim KC: Membrane-tethered MUC1 mucin is phosphorylated by epidermal growth factor receptor in airway epithelial cells and associates with TLR5 to inhibit recruitment of MyD88. J Immunol 2012;188:2014-2022.

- 48 Singh PK, Behrens ME, Eggers JP, Cerny RL, Bailey JM, Shanmugam K, Gendler SJ, Bennett EP, Hollingsworth MA: Phosphorylation of MUC1 by Met modulates interaction with p53 and MMP1 expression. J Biol Chem 2008; 283:26985-26995.

49 Li Y, Kuwahara H, Ren J, Wen G, Kufe D: The c-Src tyrosine kinase regulates signaling of the human DF3/MUC1 carcinoma-associated antigen with GSK3 $\beta$ and $\beta$-catenin. J Biol Chem 2001;276:6061-6064.

50 Huang L, Chen D, Liu D, Yin L, Kharbanda S, Kufe D: MUC1 oncoprotein blocks glycogen synthase kinase $3 \beta$-mediated phosphorylation and degradation of $\beta$-catenin. Cancer Res 2005; 65:10413-10422.

51 Sheng YH, Triyana S, Wang R, Das I, Gerloff $\mathrm{K}$, Florin $\mathrm{TH}$, Sutton $\mathrm{P}$, McGuckin MA: MUC1 and MUC13 differentially regulate epithelial inflammation in response to inflammatory and infectious stimuli. Mucosal Immunol 2013;6:557-568.

52 Brown MS, Ye J, Rawson RB, Goldstein JL: Regulated intramembrane proteolysis: a control mechanism conserved from bacteria to humans. Cell 2000;100:391-398.

53 Andersson CX, Fernandez-Rodriguez J, Laos S, Baeckstrom D, Haass C, Hansson GC: Shedding and $\gamma$-secretase-mediated intramembrane proteolysis of the mucin-type molecule CD43. Biochem J 2005;387:377384.

54 Hinojosa-Kurtzberg AM, Johansson ME, Madsen CS, Hansson GC, Gendler SJ: Novel MUC1 splice variants contribute to mucin overexpression in CFTR-deficient mice. Am J Physiol Gastrointest Liver Physiol 2003; 284:G853-G862.

55 Imbert Y, Darling DS, Jumblatt MM, Foulks GN, Couzin EG, Steele PS, Young WW Jr: MUC1 splice variants in human ocular surface tissues: possible differences between dry eye patients and normal controls. Exp Eye Res 2006;83:493-501.

56 Imbert-Fernandez Y, Radde BN, Teng Y, Young WW Jr, Hu C, Klinge CM: MUC1/A and MUC1/B splice variants differentially regulate inflammatory cytokine expression. Exp Eye Res 2011;93:649-657.
7 Obermair A, Schmid BC, Stimpfl M, Fasching B, Preyer O, Leodolter S, Crandon AJ, Zeillinger R: Novel MUC1 splice variants are expressed in cervical carcinoma. Gynecol Oncol 2001;83:343-347.

58 Kahkhaie KR, Moaven O, Abbaszadegan MR, Montazer M, Gholamin M: Specific MUC1 splice variants are correlated with tumor progression in esophageal cancer. World J Surg 2014;38:2052-2057.

59 Frey A, Giannasca KT, Weltzin R, Giannasca PJ, Reggio H, Lencer WI, Neutra MR: Role of the glycocalyx in regulating access of microparticles to apical plasma membranes of intestinal epithelial cells: implications for microbial attachment and oral vaccine targeting. J Exp Med 1996;184:1045-1059.

60 Bramwell ME, Wiseman G, Shotton DM: Electron-microscopic studies of the CA antigen, epitectin. J Cell Sci 1986;86:249-261.

61 Cone RA: Barrier properties of mucus. Adv Drug Deliv Rev 2009;61:75-85.

62 Kesimer M, Ehre C, Burns KA, Davis CW, Sheehan JK, Pickles RJ: Molecular organization of the mucins and glycocalyx underlying mucus transport over mucosal surfaces of the airways. Mucosal Immunol 2013;6:379-392.

63 Linden SK, Florin TH, McGuckin MA: Mucin dynamics in intestinal bacterial infection. PLoS One 2008;3:e3952.

-64 Linden S, Nordman H, Hedenbro J, Hurtig M, Boren T, Carlstedt I: Strain- and blood groupdependent binding of Helicobacter pylori to human gastric MUC5AC glycoforms. Gastroenterology 2002;123:1923-1930.

65 McGuckin MA, Every AL, Skene CD, Linden SK, Chionh YT, Swierczak A, McAuley J, Harbour S, Kaparakis M, Ferrero R, Sutton P: Mucl mucin limits both Helicobacter pylori colonization of the murine gastric mucosa and associated gastritis. Gastroenterology 2007;133:1210-1218.

66 Linden SK, Sheng YH, Every AL, Miles KM, Skoog EC, Florin TH, Sutton P, McGuckin MA: MUC1 limits Helicobacter pylori infection both by steric hindrance and by acting as a releasable decoy. PLoS Pathog 2009;5: e1000617.

-67 Vinall LE, King M, Novelli M, Green CA, Daniels G, Hilkens J, Sarner M, Swallow DM: Altered expression and allelic association of the hypervariable membrane mucin MUC1 in Helicobacter pylori gastritis. Gastroenterology 2002;123:41-49.

68 McAuley JL, Linden SK, Png CW, King RM, Pennington HL, Gendler SJ, Florin TH, Hill GR, Korolik V, McGuckin MA: MUC1 cell surface mucin is a critical element of the mucosal barrier to infection. J Clin Invest 2007; 117:2313-2324.

69 Ermund A, Gustafsson JK, Hansson GC, Keita AV: Mucus properties and goblet cell quantification in mouse, rat and human ileal Peyer's patches. PLoS One 2013;8:e83688. 
-70 Lu W, Hisatsune A, Koga T, Kato K, Kuwahara I, Lillehoj EP, Chen W, Cross AS, Gendler SJ, Gewirtz AT, Kim KC: Cutting edge: enhanced pulmonary clearance of Pseudomonas aeruginosa by Muc1 knockout mice. J Immunol 2006; 176:3890-3894.

-71 Umehara T, Kato K, Park YS, Lillehoj EP, Kawauchi H, Kim KC: Prevention of lung injury by Muc1 mucin in a mouse model of repetitive Pseudomonas aeruginosa infection. Inflamm Res 2012;61:1013-1020.

72 Kato K, Lillehoj EP, Kim KC: Pseudomonas aeruginosa stimulates tyrosine phosphorylation of and TLR5 association with the MUC1 cytoplasmic tail through EGFR activation. Inflamm Res 2016;65:225-233.

73 Lillehoj EP, Kim H, Chun EY, Kim KC: Pseudomonas aeruginosa stimulates phosphorylation of the airway epithelial membrane glycoprotein Mucl and activates MAP kinase. Am J Physiol Lung Cell Mol Physiol 2004;287:L809-L815.

74 Vieira MA, Gomes TA, Ferreira AJ, Knobl T, Servin AL, Lievin-Le Moal V: Two atypical enteropathogenic Escherichia coli strains induce the production of secreted and membrane-bound mucins to benefit their own growth at the apical surface of human mucinsecreting intestinal HT29-MTX cells. Infect Immun 2010;78:927-938.

75 Luo Q, Kumar P, Vickers TJ, Sheikh A, Lewis WG, Rasko DA, Sistrunk J, Fleckenstein JM: Enterotoxigenic Escherichia coli secretes a highly conserved mucin-degrading metalloprotease to effectively engage intestinal epithelial cells. Infect Immun 2014;82:509-521.

76 Mack DR, Ahrne S, Hyde L, Wei S, Hollingsworth MA: Extracellular MUC3 mucin secretion follows adherence of Lactobacillus strains to intestinal epithelial cells in vitro. Gut 2003; 52:827-833.

77 Zhou C, Liu Z, Liu Y, Fu W, Ding X, Liu J, Yu Y, Zhang Q: Gene silencing of porcine MUC13 and ITGB5: candidate genes towards Escherichia coli F4ac adhesion. PLoS One 2013;8:e70303.

78 Ren J, Yan X, Ai H, Zhang Z, Huang X, Ouyang J, Yang M, Yang H, Han P, Zeng W, Chen Y, Guo Y, Xiao S, Ding N, Huang L: Susceptibility towards enterotoxigenic Escherichia coli F4ac diarrhea is governed by the MUC13 gene in pigs. PLoS One 2012; 7:e44573.

79 Goetstouwers T, van Poucke M, Coppieters W, Nguyen VU, Melkebeek V, Coddens A, Van Steendam K, Deforce D, Cox E, Peelman LJ: Refined candidate region for F4ab/ac enterotoxigenic Escherichia coli susceptibility situated proximal to MUC13 in pigs. PLoS One 2014;9:e105013.

-80 Kim SH, Chi M, Yi B, Kim SH, Oh S, Kim Y, Park S, Sung JH: Three-dimensional intestinal villi epithelium enhances protection of human intestinal cells from bacterial infection by inducing mucin expression. Integr Biol 2014;6:1122-1131.
81 Moehle C, Ackermann N, Langmann T, Aslanidis C, Kel A, Kel-Margoulis O, SchmitzMadry A, Zahn A, Stremmel W, Schmitz G: Aberrant intestinal expression and allelic variants of mucin genes associated with inflammatory bowel disease. J Mol Med 2006; 84:1055-1066.

82 Kyo K, Muto T, Nagawa H, Lathrop GM, Nakamura Y: Associations of distinct variants of the intestinal mucin gene MUC3A with ulcerative colitis and Crohn's disease. J Hum Genet 2001;46:5-20.

83 Sheng YH, Lourie R, Linden SK, Jeffery PL, Roche D, Tran TV, Png CW, Waterhouse N, Sutton P, Florin TH, McGuckin MA: The MUC13 cell-surface mucin protects against intestinal inflammation by inhibiting epithelial cell apoptosis. Gut 2011;60:1661-1670.

84 Liu C, Smet A, Blaecher C, Flahou B, Ducatelle R, Linden S, Haesebrouck F: Gastric de novo Muc13 expression and spasmolytic polypeptide-expressing metaplasia during Helicobacter heilmannii infection. Infect Immun 2014;82:3227-3239.

85 Das S, Rachagani S, Sheinin Y, Smith LM, Gurumurthy CB, Roy HK, Batra SK: Mice deficient in Muc4 are resistant to experimental colitis and colitis-associated colorectal cancer. Oncogene 2016;35:2645-2654.

86 van Seuningen I, Pigny P, Perrais M, Porchet $\mathrm{N}$, Aubert JP: Transcriptional regulation of the $11 \mathrm{p} 15$ mucin genes: towards new biological tools in human therapy, in inflammatory diseases and cancer? Front Biosci 2001;6: D1216-D1234.

87 Gaemers IC, Vos HL, Volders HH, van der Valk SW, Hilkens J: A stat-responsive element in the promoter of the episialin/MUC1 gene is involved in its overexpression in carcinoma cells. J Biol Chem 2001;276:6191-6199.

88 Gupta BK, Maher DM, Ebeling MC, Stephenson PD, Puumala SE, Koch MR, Aburatani H, Jaggi M, Chauhan SC: Functions and regulation of MUC13 mucin in colon cancer cells. J Gastroenterol 2014;49:1378-1391.

89 Morgado M, Sutton MN, Simmons M, Warren CR, Lu Z, Constantinou PE, Liu J, Francis LL, Conlan RS, Bast RC Jr, Carson DD: Tumor necrosis factor- $\alpha$ and interferon- $\gamma$ stimulate MUC16 (CA125) expression in breast, endometrial and ovarian cancers through NFкB. Oncotarget 2016;7:14871-14884.

$\$ 90$ Fischer BM, Cuellar JG, Diehl ML, deFreytas AM, Zhang J, Carraway KL, Voynow JA: Neutrophil elastase increases MUC4 expression in normal human bronchial epithelial cells. Am J Physiol Lung Cell Mol Physiol 2003;284: L671-L679.

91 Lomako WM, Lomako J, Soto P, Carraway CA, Carraway KL: TGF $\beta$ regulation of membrane mucin Muc4 via proteosome degradation. J Cell Biochem 2009;107:797-802.

92 Guang W, Ding H, Czinn SJ, Kim KC, Blanchard TG, Lillehoj EP: Muc1 cell surface mucin attenuates epithelial inflammation in response to a common mucosal pathogen. J Biol Chem 2010;285:20547-20557.
93 Ahmad R, Raina D, Trivedi V, Ren J, Rajabi H, Kharbanda S, Kufe D: MUC1 oncoprotein activates the I $\kappa B$ kinase $\beta$ complex and constitutive NF- $\kappa B$ signalling. Nat Cell Biol 2007;9:1419-1427.

94 Ahmad R, Raina D, Joshi MD, Kawano T, Ren J, Kharbanda S, Kufe D: MUC1-C oncoprotein functions as a direct activator of the nuclear factor- $\kappa B$ p 65 transcription factor. Cancer Res 2009;69:7013-7021.

95 Cascio S, Zhang L, Finn OJ: MUC1 protein expression in tumor cells regulates transcription of proinflammatory cytokines by forming a complex with nuclear factor- $\mathrm{kB}$ p65 and binding to cytokine promoters: importance of extracellular domain. J Biol Chem 2011;286:42248-42256.

$\$ 96$ Ueno K, Koga T, Kato K, Golenbock DT, Gendler SJ, Kai H, Kim KC: MUC1 mucin is a negative regulator of toll-like receptor signaling. Am J Respir Cell Mol Biol 2008; 38:263-268.

-97 Kato K, Lillehoj EP, Kim KC: MUC1 regulates epithelial inflammation and apoptosis by PolyI:C through inhibition of Toll/ IL-1 receptor-domain-containing adapterinducing IFN- $\beta$ (TRIF) recruitment to Tolllike receptor 3. Am J Respir Cell Mol Biol 2014;51:446-454.

$\$ 98$ Menon BB, Kaiser-Marko C, Spurr-Michaud S, Tisdale AS, Gipson IK: Suppression of Toll-like receptor-mediated innate immune responses at the ocular surface by the membrane-associated mucins MUC1 and MUC16. Mucosal Immunol 2015;8: 1000-1008.

-99 Kyo Y, Kato K, Park YS, Gajghate S, Umehara T, Lillehoj EP, Suzaki H, Kim KC: Antiinflammatory role of MUC1 mucin during infection with nontypeable Haemophilus influenzae. Am J Respir Cell Mol Biol 2012;46: 149-156.

100 Ng GZ, Sutton P: The MUC1 mucin specifically inhibits activation of the NLRP3 inflammasome. Genes Immun 2016;17:203206.

101 Kato K, Uchino R, Lillehoj EP, Knox K, Lin Y, Kim KC: Membrane-tethered MUC1 mucin counter-regulates the phagocytic activity of macrophages. Am J Respir Cell Mol Biol 2016;54:515-523.

102 Williams MA, Bauer S, Lu W, Guo J, Walter S, Bushnell TP, Lillehoj EP, Georas SN: Deletion of the mucin-like molecule mucl enhances dendritic cell activation in response to toll-like receptor ligands. J Innate Immun 2010;2:123-143.

-103 Ng GZ, Menheniott TR, Every AL, Stent A, Judd LM, Chionh YT, Dhar P, Komen JC, Giraud AS, Wang TC, McGuckin MA, Sutton P: The MUC1 mucin protects against Helicobacter pylori pathogenesis in mice by regulation of the NLRP3 inflammasome. Gut 2016;65:1087-1099. 
104 Agrawal B, Krantz MJ, Parker J, Longenecker BM: Expression of MUC1 mucin on activated human T cells: implications for a role of MUC1 in normal immune regulation. Cancer Res 1998;58:4079-4081.

-105 van de Wiel-van Kemenade E, Ligtenberg MJ, de Boer AJ, Buijs F, Vos HL, Melief CJ, Hilkens J, Figdor CG: Episialin (MUC1) inhibits cytotoxic lymphocyte-target cell interaction. J Immunol 1993;151:767-776.

106 McDermott KM, Crocker PR, Harris A, Burdick MD, Hinoda Y, Hayashi T, Imai K, Hollingsworth MA: Overexpression of MUC1 reconfigures the binding properties of tumor cells. Int J Cancer 2001;94:783791.

-107 Spicer AP, Rowse GJ, Lidner TK, Gendler SJ: Delayed mammary tumor progression in Muc-1 null mice. J Biol Chem 1995;270: 30093-30101.

108 Kitamoto S, Yamada N, Yokoyama S, Houjou I, Higashi M, Goto M, Batra SK, Yonezawa S: DNA methylation and histone H3-K9 modifications contribute to MUC17 expression. Glycobiology 2011;21:247-256.

109 Vincent A, Ducourouble MP, van Seuningen I: Epigenetic regulation of the human mucin gene MUC4 in epithelial cancer cell lines involves both DNA methylation and histone modifications mediated by DNA methyltransferases and histone deacetylases. FASEB J 2008;22:3035-3045.

110 Gupta BK, Maher DM, Ebeling MC, Sundram V, Koch MD, Lynch DW, Bohlmeyer T, Watanabe A, Aburatani H, Puumala SE, Jaggi M, Chauhan SC: Increased expression and aberrant localization of mucin 13 in metastatic colon cancer. J Histochem Cytochem 2012;60:822-831.

-111 Yang CW, Chang CY, Lai MT, Chang HW, Lu CC, Chen Y, Chen CM, Lee SC, Tsai PW, Yang SH, Lin CH, Sheu JJ, Tsai FJ: Genetic variations of $M U C 17$ are associated with endometriosis development and related infertility. BMC Med Genet 2015;16:60.

-112 Lange T, Samatov TR, Tonevitsky AG, Schumacher U: Importance of altered glycoprotein-bound $\mathrm{N}$ - and O-glycans for epithelial-to-mesenchymal transition and adhesion of cancer cells. Carbohydr Res 2014; 389:39-45.

-113 Lan MS, Hollingsworth MA, Metzgar RS: Polypeptide core of a human pancreatic tumor mucin antigen. Cancer Res 1990;50: 2997-3001.

114 Hanisch FG, Muller S: MUC1: the polymorphic appearance of a human mucin. Glycobiology 2000;10:439-449.

115 Bast RC Jr, Feeney M, Lazarus H, Nadler LM, Colvin RB, Knapp RC: Reactivity of a monoclonal antibody with human ovarian carcinoma. J Clin Invest 1981;68:13311337.
16 Klug TL, Bast RC Jr, Niloff JM, Knapp RC, Zurawski VR Jr: Monoclonal antibody immunoradiometric assay for an antigenic determinant (CA 125) associated with human epithelial ovarian carcinomas. Cancer Res 1984;44:1048-1053.

117 Magnani JL, Steplewski Z, Koprowski H, Ginsburg V: Identification of the gastrointestinal and pancreatic cancer-associated antigen detected by monoclonal antibody 19-9 in the sera of patients as a mucin. Cancer Res 1983;43:5489-5492.

118 Neville AM, Foster C, Redding H, Coombes RC: Monoclonal antibodies as probes of human breast disorders. Ann NY Acad Sci 1983;417:251-261.

119 Maher DM, Gupta BK, Nagata S, Jaggi M, Chauhan SC: Mucin 13: structure, function, and potential roles in cancer pathogenesis. Mol Cancer Res 2011;9:531-537.

120 Gout S, Tremblay PL, Huot J: Selectins and selectin ligands in extravasation of cancer cells and organ selectivity of metastasis. Clin Exp Metastasis 2008;25:335-344.

121 Zhang K, Baeckstrom D, Brevinge H, Hansson GC: Secreted MUC1 mucins lacking their cytoplasmic part and carrying sialylLewis a and $x$ epitopes from a tumor cell line and sera of colon carcinoma patients can inhibit HL-60 leukocyte adhesion to E-selectin-expressing endothelial cells. J Cell Biochem 1996;60:538-549.

122 Wesseling J, van der Valk SW, Vos HL, Sonnenberg A, Hilkens J: Episialin (MUC1) overexpression inhibits integrin-mediated cell adhesion to extracellular matrix components. J Cell Biol 1995;129:255-265.

123 Yu LG, Andrews N, Zhao Q, McKean D, Williams JF, Connor LJ, Gerasimenko OV, Hilkens J, Hirabayashi J, Kasai K, Rhodes JM: Galectin-3 interaction with ThomsenFriedenreich disaccharide on cancer-associated MUC1 causes increased cancer cell endothelial adhesion. J Biol Chem 2007;282: 773-781.

124 Zhao Q, Guo X, Nash GB, Stone PC, Hilkens J, Rhodes JM, Yu LG: Circulating galectin-3 promotes metastasis by modifying MUC1 localization on cancer cell surface. Cancer Res 2009;69:6799-6806.

125 Zhao Q, Piyush T, Chen C, Hollingsworth MA, Hilkens J, Rhodes JM, Yu LG: MUC1 extracellular domain confers resistance of epithelial cancer cells to anoikis. Cell Death Dis 2014;5:e1438.

126 Wang Q, Yu LG, Campbell BJ, Milton JD, Rhodes JM: Identification of intact peanut lectin in peripheral venous blood. Lancet 1998;352:1831-1832.

127 Zhao Q, Duckworth CA, Wang W, Guo X, Barrow H, Pritchard DM, Rhodes JM, Yu LG: Peanut agglutinin appearance in the blood circulation after peanut ingestion mimics the action of endogenous galectin- 3 to promote metastasis by interaction with cancer-associated MUC1. Carcinogenesis 2014;35:2815-2821.
28 Hayashi T, Takahashi T, Motoya S, Ishida T, Itoh F, Adachi M, Hinoda Y, Imai K: MUC1 mucin core protein binds to the domain 1 of ICAM-1. Digestion 2001;63(suppl 1):87-92.

129 Rahn JJ, Shen Q, Mah BK, Hugh JC: MUC1 initiates a calcium signal after ligation by intercellular adhesion molecule-1. J Biol Chem 2004;279:29386-29390.

130 Kohlgraf KG, Gawron AJ, Higashi M, Meza JL, Burdick MD, Kitajima S, Kelly DL, Caffrey TC, Hollingsworth MA: Contribution of the MUC1 tandem repeat and cytoplasmic tail to invasive and metastatic properties of a pancreatic cancer cell line. Cancer Res 2003;63:5011-5020.

131 Swanson BJ, McDermott KM, Singh PK, Eggers JP, Crocker PR, Hollingsworth MA: MUC1 is a counter-receptor for myelin-associated glycoprotein (Siglec-4a) and their interaction contributes to adhesion in pancreatic cancer perineural invasion. Cancer Res 2007;67:10222-10229.

132 Ren J, Agata N, Chen D, Li Y, Yu WH, Huang L, Raina D, Chen W, Kharbanda S, Kufe D: Human MUC1 carcinoma-associated protein confers resistance to genotoxic anticancer agents. Cancer Cell 2004;5:163175.

133 Komatsu M, Carraway CA, Fregien NL, Carraway KL: Reversible disruption of cellmatrix and cell-cell interactions by overexpression of sialomucin complex. J Biol Chem 1997;272:33245-33254.

134 Wang R, Yu C, Zhao D, Wu M, Yang Z: The mucin-type glycosylating enzyme polypeptide $\mathrm{N}$-acetylgalactosaminyltransferase 14 promotes the migration of ovarian cancer by modifying mucin 13 . Oncol Rep 2013;30: 667-676.

135 Chen SH, Hung WC, Wang P, Paul C, Konstantopoulos K: Mesothelin binding to CA125/MUC16 promotes pancreatic cancer cell motility and invasion via MMP-7 activation. Sci Rep 2013;3:1870.

136 Yamamoto M, Bharti A, Li Y, Kufe D: Interaction of the DF3/MUC1 breast carcinomaassociated antigen and $\beta$-catenin in cell adhesion. J Biol Chem 1997;272:12492-12494.

137 Quin RJ, McGuckin MA: Phosphorylation of the cytoplasmic domain of the MUC1 mucin correlates with changes in cell-cell adhesion. Int J Cancer 2000;87:499-506.

138 Li Y, Bharti A, Chen D, Gong J, Kufe D: Interaction of glycogen synthase kinase $3 \beta$ with the DF3/MUC1 carcinoma-associated antigen and $\beta$-catenin. Mol Cell Biol 1998; 18:7216-7224.

139 Ren J, Li Y, Kufe D: Protein kinase C delta regulates function of the DF3/MUC1 carcinoma antigen in $\beta$-catenin signaling. J Biol Chem 2002;277:17616-17622.

140 Huang L, Ren J, Chen D, Li Y, Kharbanda S, Kufe D: MUC1 cytoplasmic domain coactivates Wnt target gene transcription and confers transformation. Cancer Biol Ther 2003;2:702-706. 
141 Giannakouros P, Comamala M, Matte I, Rancourt C, Piche A: MUC16 mucin (CA125) regulates the formation of multicellular aggregates by altering $\beta$-catenin signaling. Am J Cancer Res 2015;5:219-230.

142 Wen Y, Caffrey TC, Wheelock MJ, Johnson KR, Hollingsworth MA: Nuclear association of the cytoplasmic tail of MUC1 and $\beta$-catenin. J Biol Chem 2003;278:3802938039.

143 Singh PK, Wen Y, Swanson BJ, Shanmugam K, Kazlauskas A, Cerny RL, Gendler SJ, Hollingsworth MA: Platelet-derived growth factor receptor $\beta$-mediated phosphorylation of MUC1 enhances invasiveness in pancreatic adenocarcinoma cells. Cancer Res 2007;67:5201-5210.

144 Liu X, Caffrey TC, Steele MM, Mohr A, Singh PK, Radhakrishnan P, Kelly DL, Wen Y, Hollingsworth MA: MUC1 regulates cyclin D1 gene expression through p120 catenin and $\beta$-catenin. Oncogenesis 2014; 3:e107.

145 Baldus SE, Monig SP, Huxel S, Landsberg S, Hanisch FG, Engelmann K, Schneider PM, Thiele J, Holscher AH, Dienes HP: MUC1 and nuclear $\beta$-catenin are coexpressed at the invasion front of colorectal carcinomas and are both correlated with tumor prognosis. Clin Cancer Res 2004;10:2790-2796.

146 Wei X, Xu H, Kufe D: Human mucin 1 oncoprotein represses transcription of the p53 tumor suppressor gene. Cancer Res 2007; 67:1853-1858.

147 Wei X, Xu H, Kufe D: MUC1 oncoprotein stabilizes and activates estrogen receptor $\alpha$. Mol Cell 2006;21:295-305.
148 Das S, Rachagani S, Torres-Gonzalez MP, Lakshmanan I, Majhi PD, Smith LM, Wagner KU, Batra SK: Carboxyl-terminal domain of MUC16 imparts tumorigenic and metastatic functions through nuclear translocation of JAK2 to pancreatic cancer cells. Oncotarget 2015;6:5772-5787.

149 Yao M, Zhang W, Zhang Q, Xing L, Xu A, Liu Q, Cui B: Overexpression of MUC1 enhances proangiogenic activity of non-smallcell lung cancer cells through activation of Akt and extracellular signal-regulated kinase pathways. Lung 2011;189:453-460.

150 Woo JK, Choi Y, Oh SH, Jeong JH, Choi DH, Seo HS, Kim CW: Mucin 1 enhances the tumor angiogenic response by activation of the AKT signaling pathway. Oncogene 2012;31:2187-2198.

151 Raina D, Kharbanda S, Kufe D: The MUC1 oncoprotein activates the anti-apoptotic phosphoinositide 3-kinase/Akt and Bcl-xL pathways in rat $3 \mathrm{Y} 1$ fibroblasts. J Biol Chem 2004;279:20607-20612.

152 Lakshmanan I, Ponnusamy MP, Das S, Chakraborty S, Haridas D, Mukhopadhyay P, Lele SM, Batra SK: MUC16 induced rapid G2/M transition via interactions with JAK2 for increased proliferation and anti-apoptosis in breast cancer cells. Oncogene 2012;31: 805-817.

153 Matte I, Lane D, Boivin M, Rancourt C, Piche A: MUC16 mucin (CA125) attenuates TRAIL-induced apoptosis by decreasing TRAIL receptor R2 expression and increasing c-FLIP expression. BMC Cancer 2014; 14:234.
54 Li Y, Ren J, Yu W, Li Q, Kuwahara H, Yin L, Carraway KL 3rd, Kufe D: The epidermal growth factor receptor regulates interaction of the human DF3/MUC1 carcinoma antigen with $\mathrm{c}$-Src and $\beta$-catenin. J Biol Chem 2001;276:35239-35242.

155 Carraway KL, Carraway CA, Carraway KL 3rd: Roles of ErbB-3 and ErbB-4 in the physiology and pathology of the mammary gland. J Mammary Gland Biol Neoplasia 1997;2:187-198.

156 Schroeder JA, Thompson MC, Gardner MM, Gendler SJ: Transgenic MUC1 interacts with epidermal growth factor receptor and correlates with mitogen-activated protein kinase activation in the mouse mammary gland. J Biol Chem 2001;276:1305713064.

157 Pochampalli MR, el Bejjani RM, Schroeder JA: MUC1 is a novel regulator of ErbB1 receptor trafficking. Oncogene 2007;26:16931701.

158 Wang H, Lillehoj EP, Kim KC: MUC1 tyrosine phosphorylation activates the extracellular signal-regulated kinase. Biochem Biophys Res Commun 2004;321:448-454.

159 Carraway KL, Price-Schiavi SA, Komatsu M, Idris N, Perez A, Li P, Jepson S, Zhu X, Carvajal ME, Carraway CA: Multiple facets of sialomucin complex/MUC4, a membrane mucin and ERBB2 ligand, in tumors and tissues (Y2K update). Front Biosci 2000; 5:D95-D107.

160 Pandey P, Kharbanda S, Kufe D: Association of the DF3/MUC1 breast cancer antigen with Grb2 and the Sos/Ras exchange protein. Cancer Res 1995;55:4000-4003.

Transmembrane Mucins 